\title{
Development of a Time-Domain, Variable-Period Surface-Wave Magnitude Measurement Procedure for Application at Regional and Teleseismic Distances, Part II: Application and $M_{\mathrm{s}}-m_{\mathrm{b}}$ Performance
}

\author{
by Jessie L. Bonner, David R. Russell, David G. Harkrider, \\ Delaine T. Reiter, and Robert B. Herrmann
}

\begin{abstract}
The Russell surface-wave magnitude formula, developed in Part I of this two-part article, and the $M_{\mathrm{s}}(\mathrm{VMAX})$ measurement technique, discussed in this article, provide a new method for estimating variable-period surface-wave magnitudes at regional and teleseismic distances. The $M_{\mathrm{s}}(\mathrm{VMAX})$ measurement method consists of applying Butterworth bandpass filters to data at center periods between 8 and $25 \mathrm{sec}$. The filters are designed to help remove the effects of nondispersed Airy phases at regional and teleseismic distances. We search for the maximum amplitude in all of the variable-period bands and then use the Russell formula to calculate a surface-wave magnitude.

In this companion article, we demonstrate the capabilities of the method by using applications to three different datasets. The first application utilizes a dataset that consists of large earthquakes in the Mediterranean region. The results indicate that the $M_{\mathrm{s}}(\mathrm{VMAX})$ technique provides regional and teleseismic surface-wave magnitude estimates that are in general agreement except for a small distance dependence of -0.002 magnitude units per degree. We also find that the $M_{\mathrm{s}}(\mathrm{VMAX})$ estimates are less than 0.1 magnitude unit different than those from other formulas applied at teleseismic distances such as Rezapour and Pearce (1998) and Vanĕk et al. (1962).

In the second and third applications of the method, we demonstrate that measurements of $M_{s}(\mathrm{VMAX})$ versus $m_{\mathrm{b}}$ provide adequate separation of the explosion and earthquake populations at the Nevada and Lop Nor Test Sites. At the Nevada Test Site, our technique resulted in the misclassification of two earthquakes in the explosion population. We also determined that the new technique reduces the scatter in the magnitude estimates by $25 \%$ when compared with our previous studies using a calibrated regional magnitude formula. For the Lop Nor Test Site, we had no misclassified explosions or earthquakes; however, the data were less comprehensive.

A preliminary analysis of Eurasian earthquake and explosion data suggest that similar slopes are obtained for observed $M_{\mathrm{s}}(\mathrm{VMAX})$ versus $m_{\mathrm{b}}$ data with $m_{\mathrm{b}}<5$. Thus the data are not converging at lower magnitudes. These results suggest that the discrimination of explosions from earthquakes can be achieved at lower magnitudes using the Russell (2006) formula and the $M_{\mathrm{s}}(\mathrm{VMAX})$ measurement technique.
\end{abstract}

\section{Introduction}

The discrimination of small-to-intermediate magnitude $\left(3<m_{\mathrm{b}}<5\right)$ explosions and earthquakes remains a difficult problem for the nuclear monitoring community. For larger events, the relative difference between the body-wave $\left(m_{\mathrm{b}}\right)$ and surface-wave $\left(M_{\mathrm{s}}\right)$ magnitude for a seismic event is one of the best discriminant techniques available at teleseismic distances. The discriminant works because, at a given $m_{\mathrm{b}}$, earthquakes usually generate substantially more surface- wave energy than explosions and thus are characterized by a larger surface-wave magnitude. Difference in focal mechanisms and the near-source material velocity also helps improve the discriminant performance (Stevens and Day, 1985). At regional distances, the measurement of surfacewave amplitudes is complicated because of nondispersed Airy phases. Hence, a remaining problem for the nuclear monitoring community is to create a seamless relationship 
between estimating $M_{\mathrm{s}}$ at regional and teleseismic distances for events of a wider range of magnitudes.

Many of the surface-wave magnitude scales have been based on empirical formulas of the form:

$$
M_{\mathrm{s}}=\log A+B(\Delta)+C,
$$

where $A$ is the instrument-corrected ground motion measured in the time domain, usually in nanometers; $B(\Delta)$ is an attenuation term; and $C$ is either a station correction, a term to scale for consistency between magnitude scales, or a path correction. These latter two terms are often determined empirically by averaging across many events at various distances.

The notion of using surface waves to obtain an estimate of source size was first introduced by Gutenberg (1945) using the equation:

$$
M_{\mathrm{s}}=\log A+1.656 \log \Delta-1.182+S_{\mathrm{c}},
$$

where $A$ is the amplitude (in nanometers) of the horizontal ground motion at a period of $20 \mathrm{sec}$, and $S_{\mathrm{c}}$ is a station correction term. Vanĕk et al. (1962) improved on this scale by developing a formula that could be used at periods in the vicinity of $20 \mathrm{sec}$ over any epicentral distance. Thus for any distance $\Delta$ and period $T$ approximately $20 \mathrm{sec}$, they proposed the formula:

$$
M_{\mathrm{s}}=\log (A / T)+1.66 \log (\Delta)+0.3 .
$$

At distances greater than 25 degrees, the $M_{\mathrm{s}}$ estimates from Gutenberg (1945) and Vaněk et al. (1962), also known as the Prague formula, agree within 0.2 magnitude units (m.u.) (Marshall and Basham, 1972). However, considerable problems arose, along with confusion in the literature, when the two scales were applied to both regional and teleseismic events. This led Marshall and Basham (1972) to reformulate the Vanĕk et al. (1962) formula for use at regional and teleseismic distances; however, a path correction based on dispersion curves for shorter periods $(<20 \mathrm{sec})$ was needed to account for Airy phase effects at these distances. Other improvements to empirical formulas have been developed by von Seggern (1977) and Herak and Herak (1993).

Recently, the trend has been to constrain surface-wave magnitude formulas to the theoretical aspects of surfacewave propagation, including dispersion, attenuation, and geometrical spreading. In the frequency domain, Kanamori and Stewart (1976) described the corrected amplitude $\left(A_{\mathrm{c}}\right)$ for a surface wave at distance $\Delta$ as:

$$
A_{\mathrm{c}}=A \sqrt{r_{e} \sin (\Delta)} e^{\frac{\pi \kappa \Delta}{U Q T}}
$$

where $A$ is the frequency domain amplitude, $r_{e}$ is the radius of the earth, $\kappa$ is the degrees to kilometers distance conversion term $(111.2 \mathrm{~km} / \mathrm{deg}), U$ is the group velocity at period
$T$, and $Q$ is the period-dependent quality factor. Okal (1989) used dispersion and attenuation relations to transform equation (4) into the time domain to compare a theoretical distance correction term with empirical terms in the Prague formula. Although the theoretical and empirical terms agreed favorably at distances between 20 and 100 degrees, discrepancies occurred at regional distances.

Rezapour and Pearce (1998) sought to reconcile these discrepancies by developing a new formula for $M_{\mathrm{s}}$ defined as:

$$
\begin{aligned}
M_{s}=\log \frac{A}{T}+\frac{1}{3} \log (\Delta)+ & \frac{1}{2} \log (\sin (\Delta)) \\
& +0.0046 \Delta+2.370
\end{aligned}
$$

The Rezapour and Pearce (1998) equation was developed by using theoretical aspects of dispersion, including Airy phase propagation, as evidenced by the $1 / 3$ coefficient on the dispersion term, and geometrical spreading. However, because they did not consider frequency-dependent aspects of dispersion, the coefficient is not sufficient to account for dispersion effects at shorter periods (Bonner et al., 2003). The formula was adopted by the prototype International Data Center in 1998 for calculating surface-wave magnitudes at distances between 20 and 100 degrees; however, it is now used by the International Data Center to determine an $M_{\mathrm{s}}$ for all surface waves recorded at distances less than 100 degrees (Stevens and McLaughlin, 2001).

Russell (2006; Part I of this article) developed a timedomain method for measuring surface waves with minimum digital processing, using zero-phase Butterworth filters. The method can effectively measure surface-wave magnitudes at both regional and teleseismic distances, at variable periods between 8 and $25 \mathrm{sec}$. For applications over typical continental crusts, the magnitude equation is:

$$
\begin{aligned}
M_{\mathrm{s}(\mathrm{b})}=\log \left(a_{b}\right)+ & \frac{1}{2} \log (\sin (\Delta))+0.0031\left(\frac{20}{T}\right)^{1.8} \Delta \\
& -0.66 \log \left(\frac{20}{T}\right)-\log \left(f_{c}\right)-0.43
\end{aligned}
$$

where $a_{b}$ is the amplitude of the Butterworth-filtered surface waves (zero-to-peak in nanometers) and $f_{c} \leq 0.6 /(T \sqrt{\Delta})$ is the filter frequency of a third-order Butterworth bandpass filter with corner frequencies $1 / T-f_{c}, 1 / T+f_{c}$. At the reference period $T=20 \mathrm{sec}$, the equation is equivalent to von Seggern's formula (1977) scaled to Vaněk et al. (1962) at 50 degrees. For periods $8 \leq T \leq 25 \mathrm{sec}$, the equation is corrected to $T=20 \mathrm{sec}$, accounting for source effects, attenuation, and dispersion.

The purpose of this article is to present the results of applying the Russell (2006) formula at teleseismic and regional distances for variable-period data. First, we applied the formula to a large earthquake dataset to demonstrate the analysis method and to determine whether the regional and 
teleseismic magnitudes are unbiased with respect to each other. We compare the resulting magnitudes from the Russell equation with estimates from Vaněk et al. (1962) and Rezapour and Pearce (1998). Then, we used the formula to estimate surface-wave magnitudes for explosions and earthquakes in Eurasia and North America to examine if we could improve discrimination performance.

\section{Methodology}

The surface-wave magnitude estimation procedure currently employed at most data centers involves measuring the amplitude of surface waves near 20-sec period. In our past research projects (Bonner et al., 2003), we tried to extend the magnitude estimation to shorter periods (e.g., $7 \mathrm{sec}$ ). We determined that shorter-period surface waves could be used for magnitude estimation for events with smaller $m_{\mathrm{b}}$ values. Although the 7-sec magnitude scale formed a robust discriminant at the Nevada Test Site (NTS), it failed to provide adequate explosion/earthquake separation at other test sites where the earthquakes were deeper than typical NTS events. This was a primary factor in the development of a measurement technique for variable periods (between 8 and $25 \mathrm{sec}$ ) and magnitude estimation using the Russell (2006) formula. We refer to this technique as VMAX for Variable-period, MAXimum amplitude estimates. In the following paragraphs, we describe how we positively identify Rayleigh wave motion and apply this new magnitude estimation technique.

\section{Surface-Wave Identification}

The largest amplitudes of near-regional surface waves for shallow events in North America and Eurasia typically occur at periods less than $20 \mathrm{sec}$, and these amplitudes can often be $6-10 \mathrm{~dB}$ larger than the amplitudes measured at the 20 -sec period. Therefore, $M_{\mathrm{S}}$ scales that consider variableperiod surface waves will be applicable to lower $m_{\mathrm{b}}$ values. Note that caution must be used to ensure that the measured signals are, in fact, Rayleigh waves and not microseisms, higher-mode energy, or Love wave contamination.

After correcting for the instrument response, we employ a surface-wave processing routine that is designed to positively identify small amplitude, fundamental-mode, Rayleighwave motion. The method is applied to all events with $m_{\mathrm{b}}$ $<4.0$, because the signal-to-noise ratio (SNR) for larger events is great enough that amplitude measurements can be made by bandpass filtering the velocity records and measuring the amplitudes in a group velocity window indicative of surface waves $(2-4 \mathrm{~km} / \mathrm{sec})$. Note that this technique can be fully automated in an operational setting so that events of all magnitudes will utilize the same processing technique.

For events with $m_{\mathrm{b}}<4.0$, we first use the multiple-filter analysis technique (Dziewonski et al., 1969) to generate a group velocity dispersion curve for each event-to-station path. We then overlay the theoretical fundamental- and first- higher mode dispersion curves predicted for the path from the Stevens et al. (2001) global shear-wave model. We require overlap (similar to Stevens and McLaughlin, 2001) in the observed dispersion, plus error in the 8- to 25 -sec period band, with the predicted fundamental-mode dispersion from the Stevens et al. (2001) model.

If the event passes the dispersion test, we then determine whether the signal has retrograde elliptical particle motion and a backazimuth that is within \pm 30 degrees of the true backazimuth. We have followed the methods of Chael (1997) and Selby (2001) to determine the backazimuth that corresponds to the largest positive value, indicative of retrograde elliptical motion, in a covariance matrix formed by the Hilbert-transformed vertical component and the two horizontal components. If a given event passes the dispersion, backazimuth, and particle motion tests, we feel that we have positively identified fundamental-mode Rayleigh waves for the event of interest.

\section{Butterworth Filtering}

Once we have positively identified the fundamentalmode Rayleigh waves, we apply a series of zero-phase thirdorder Butterworth filters to the data with the corner frequencies $1 / T-f_{c}, 1 / T-f_{c}$, where $f_{c} \leq 0.6 /(T \sqrt{\Delta})$. The center periods are placed at 1 -sec intervals between 8 and $25 \mathrm{sec}$. We note that increasing this interval to $3 \mathrm{sec}$ or lowering it to $0.1 \mathrm{sec}$ will typically result in less than a $0.05-\mathrm{m}$.u. change in the resulting magnitude. We construct the envelope function of the filtered signal and measure the maximum zeroto-peak amplitude in a group velocity window between 2.0 and $4.0 \mathrm{~km} / \mathrm{sec}$. An analyst then visually confirms that the correct waveform feature is being measured-a benefit of using a time-domain measurement.

In Figure 1 we show examples of filter panels from four stations that recorded an $m_{\mathrm{b}} 5.5$ Dodecanese Islands event in August 2004. These four examples highlight characteristics of Rayleigh waves at regional and teleseismic distances that must be considered when developing a variableperiod formula at both distances. The Russell (2006) formula has been developed to account for these differences in the excitation, attenuation, and propagation of variable-period surface waves.

For example, station LAST is located only $263 \mathrm{~km}$ from the event's epicenter, and its largest surface-wave amplitude occurs at a period of $8 \mathrm{sec}$. Note that the relative amplitudes for the 20 -sec surface waves, where typical surface-wave measurements are estimated, are much smaller than the 8sec period waves. If the event had been significantly smaller than $m_{\mathrm{b}} 5.5$, the 20-sec surface waves could have disappeared below the noise level prior to the 8-sec data, and a standard $M_{\mathrm{s}}$ measurement would have been impossible to estimate.

However, we point out that even though the maximum amplitude for station LAST is visually observed at a period of $8 \mathrm{sec}$ in the first subplot of Figure 1, an 8-sec period may 

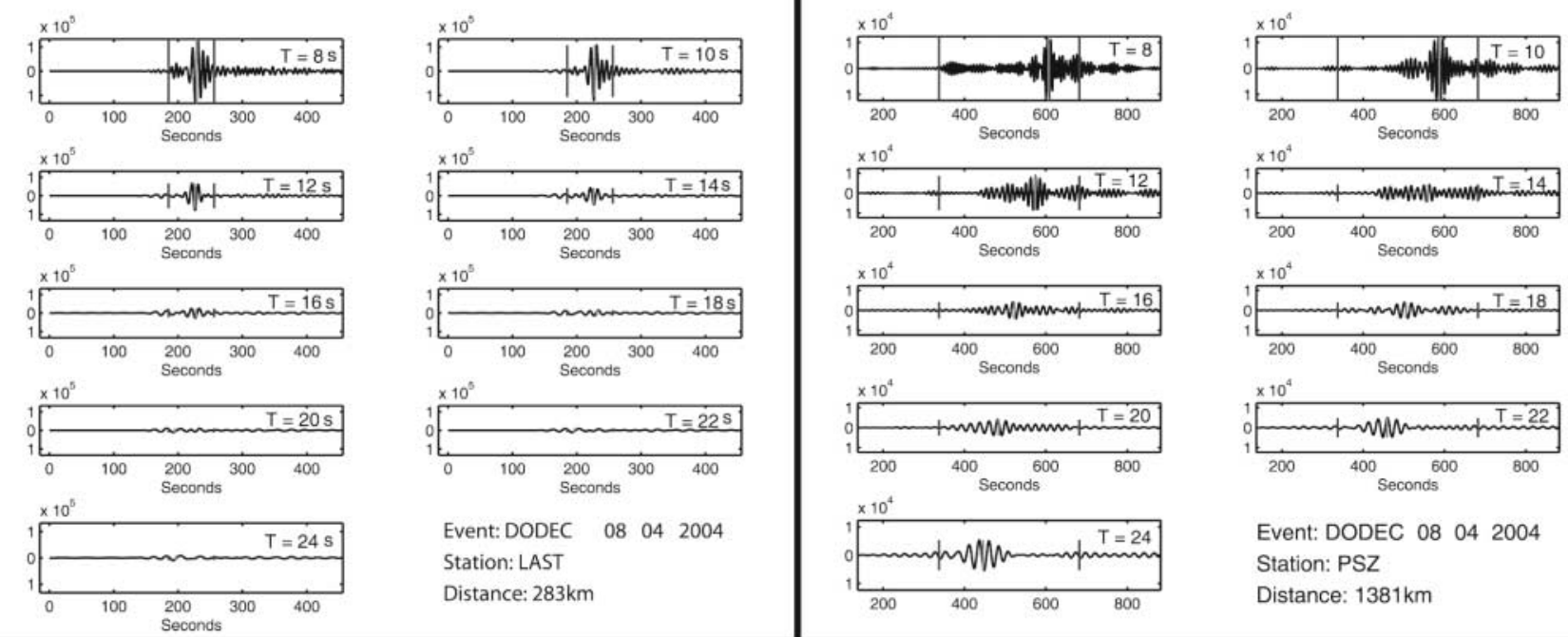

Event: DODEC $08 \quad 042004$ Station: LAST

Distance: $283 \mathrm{~km}$

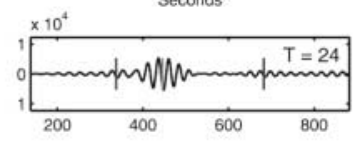

Event: DODEC 08042004 Station: PSZ

Distance: $1381 \mathrm{~km}$
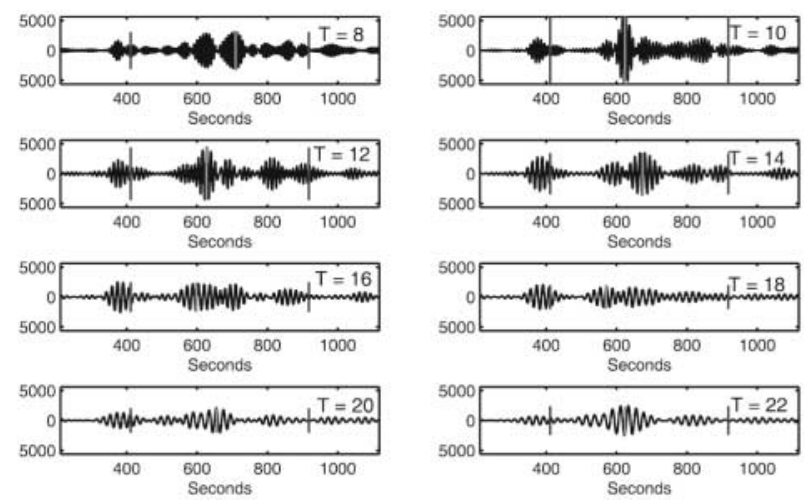

Event: DODEC 08042004 Station: BFO

Distance: $2026 \mathrm{~km}$
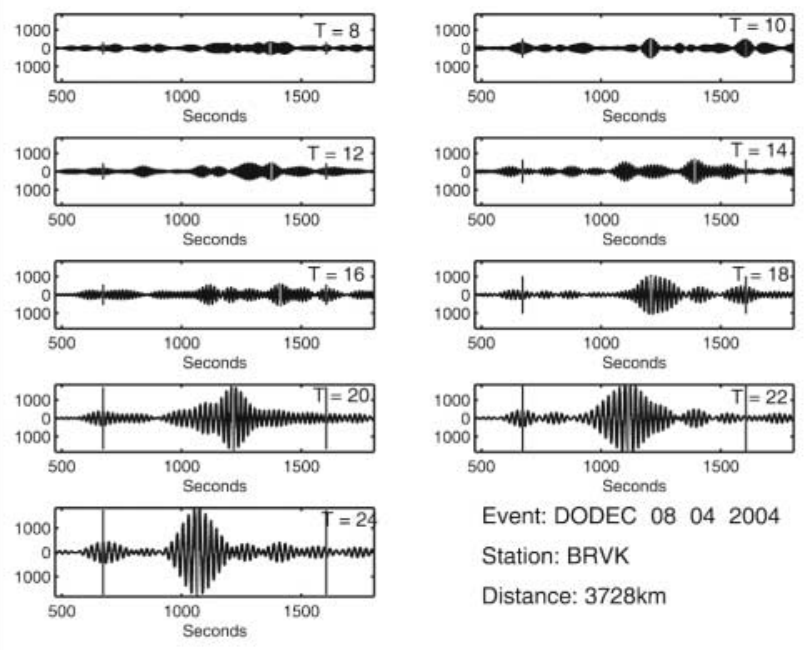

Event: DODEC 08042004

Station: BRVK

Distance: $3728 \mathrm{~km}$

Figure 1. Examples of Butterworth-filtered seismograms for a Dodecanese Islands event recorded at LAST, PSV, BFO, and BRVK. In each subplot, the $y$ axis is presented with the same amplitude scale. The $x$ axis is time in seconds from the event origin. Each filter panel has two vertical lines that represent group velocity windows of 2.0 and $4.0 \mathrm{~km} / \mathrm{sec}$. The location of the maximum amplitude at each center period is also marked by a thin vertical line.

not be considered when we average stations for a final magnitude (as discussed in the following section of this article). This is because the bandwidth chosen for filtering varies according to the formula $f_{c} \leq 0.6 /(T \sqrt{\Delta})$, to remove the effects of Airy phases. To correct the variable bandwidth to equivalent spectral amplitudes and thus get the true period of the maximum amplitude, the log amplitude data must be corrected by using a $\log \left(f_{c}\right)$ factor. Note that the same amplitude-correction effect is taken into account in equation (6) for magnitude estimation. We find that amplitude correction at station LAST results in a maximum amplitude at a period of $9 \mathrm{sec}$, which is the period used to form a network average magnitude.
For station PSZ at 1,381 km, the largest amplitude visually occurs at 8 -sec period, and the amplitude difference between the filter bands decreases as the period increases. The decrease in the difference between the shorter- and longer-period surface waves results in a period of maximum Airy-corrected amplitude at $25 \mathrm{sec}$. After the surface waves have traveled $2026 \mathrm{~km}$ to BFO, the filtered amplitudes at periods of $10 \mathrm{sec}$ are the largest for this event. After correction for the Airy phase filtering term, the period of maximum amplitude becomes $25 \mathrm{sec}$ However, when the surface waves arrive at typical teleseismic distances (e.g., station BRVK at $3728 \mathrm{~km}$ ), the largest amplitude surface waves (both visually and corrected) have a period of $23 \mathrm{sec}$. 
Estimating the Magnitude

We record the maximum amplitude in each of the 18 filter bands and then use equation (6) to calculate a variableperiod surface-wave magnitude. As noted in Figure 2, 18 different magnitudes are estimated for each station recording the event. For operational purposes, the technique will be simplified to search for the maximum corrected amplitude over all filter bands, thus reducing the number of magnitudes to be calculated from 18 to 1 . However, for research purposes, it helps to understand the method to calculate magnitudes for each filter band.

We tried several different techniques to determine the final magnitude from the analysis of surface-wave data presented in Figure 2. For instance, for the $M_{\mathrm{s}}(\mathrm{VMAX})$ technique, we search the variable-period filtered data to determine the period of the maximum Airy-corrected amplitude. Then we use the uncorrected amplitude at that period for the final magnitude estimation. We use the uncorrected amplitude because of the $\log \left(f_{c}\right)$ term in equation (6). The black large solid circles in Figure 2 show the period of the maximum Airy-corrected amplitudes and the magnitudes for the filtered data shown in Figure 1. In addition to the $M_{\mathrm{s}}$ (VMAX) technique, we have also studied a maximum-magnitude technique in which we determine the maximum magnitude over all the estimates in Figure 2. Using this method we determined that there was 0.02 magnitude unit increase in the average values.

In another comparison, we calculated a mean magnitude using the magnitude estimates from the 8- to 25-sec period band; however, this technique did not work when holes in the earthquake spectra were encountered or when the higherfrequency data were attenuated at teleseismic distances. As shown in Figure 2, the shorter-period data for station BRVK have been attenuated. Our results will be improperly biased if we average the estimates over the 18 periods. In contrast, by using the period of maximum Airy-corrected amplitude in the $M_{\mathrm{s}}(\mathrm{VMAX})$ formula, we are able to diminish any influence that spectral holes or attenuation effects may have in the magnitude estimation.

As noted in the introduction, another goal of this article is to demonstrate that the $M_{\mathrm{s}}(\mathrm{VMAX})$ formula is valid for both the regional and teleseismic surface-wave estimates. A regression of the estimates with epicentral distance shows that there is a $0.001-$ m.u. decrease per degree for these four stations that recorded this Dodecanese event on both regional (LAST and PSV) and teleseismic stations (BFO and BRVK).

\section{Excitation Correction}

The source spectra for Rayleigh waves generated from shallow explosions will typically be enriched in short-period surface wave energy. Thus the term $0.66 \log (20 / T)$ in equation (6) is a source excitation correction. The correction was determined by considering synthetics generated from nuclear explosions at $1 \mathrm{~km}$ depth in various crustal velocity
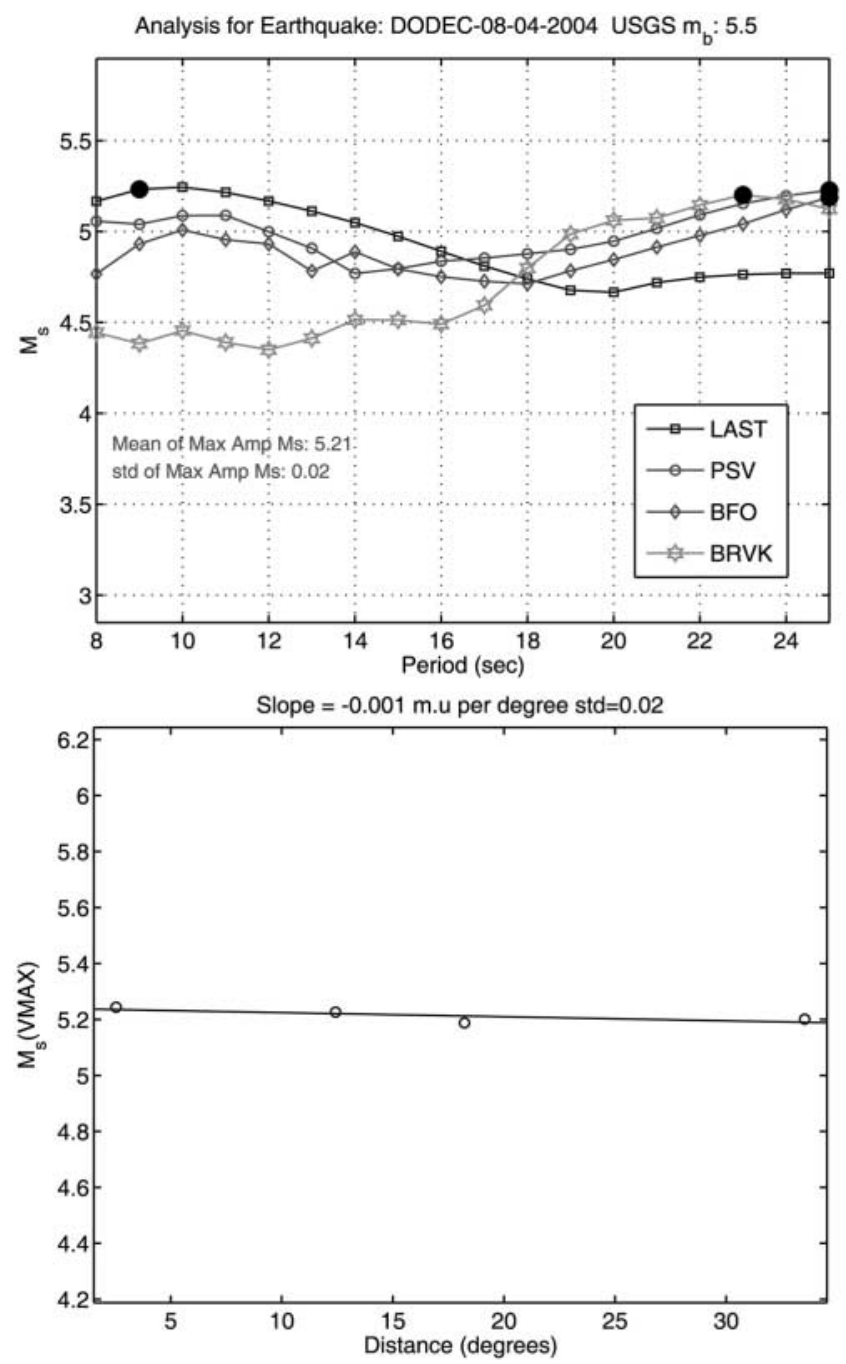

Figure 2. (Top) Example of the magnitude estimation technique $M_{\mathrm{s}}(\mathrm{VMAX})$ for the Butterworth bandpass-filtered data shown in Figure 1. The symbols show the magnitudes estimated using equation (6) at each center period. The larger filled circles show the period of maximum amplitude for the filtered seismic data corrected by a $\log \left(f_{c}\right)$ term, and the average and standard deviation of these four estimates are provided. (Bottom) Linear regression of the magnitudes versus distance for the four estimates in the top subplot.

structures (as discussed in Bonner et al., 2004). We apply the correction to all events even though it was developed with a shallow explosion assumption. This is essentially the same procedure as Stevens and McLaughlin (2001), except that they used spectral instead of time-domain measurements and derived the source and receiver functions from earth models.

To illustrate the effect of the corrections on our data, we present the $M_{\mathrm{s}}(\mathrm{VMAX})$ analysis of three near-regional recordings of NTS explosions (Fig. 3). The upper plot shows the magnitudes calculated by using the same techniques pre- 
sented in Figure 2 (e.g., using equation 6). We have applied the excitation correction to these data and determined the magnitude to be 4.13. However, in the lower plot, we did not apply the excitation correction and the enriched shortperiod energy for the nuclear explosion is evident. We have estimated a magnitude of 4.38 for these uncorrected data, which represents a 0.25 -m.u. increase over the corrected results. Using the uncorrected estimate would result in decreased effectiveness of the $M_{\mathrm{s}}-m_{\mathrm{b}}$ discriminant.

The goal of the excitation correction is to flatten the explosion $M_{\mathrm{s}}$ curves across the various periods. We are approaching that goal in Figure 3 for near-regional recordings of NTS explosions. To improve on corrections in other regions, we could use empirically determined source corrections measured from previous explosions. For this initial test
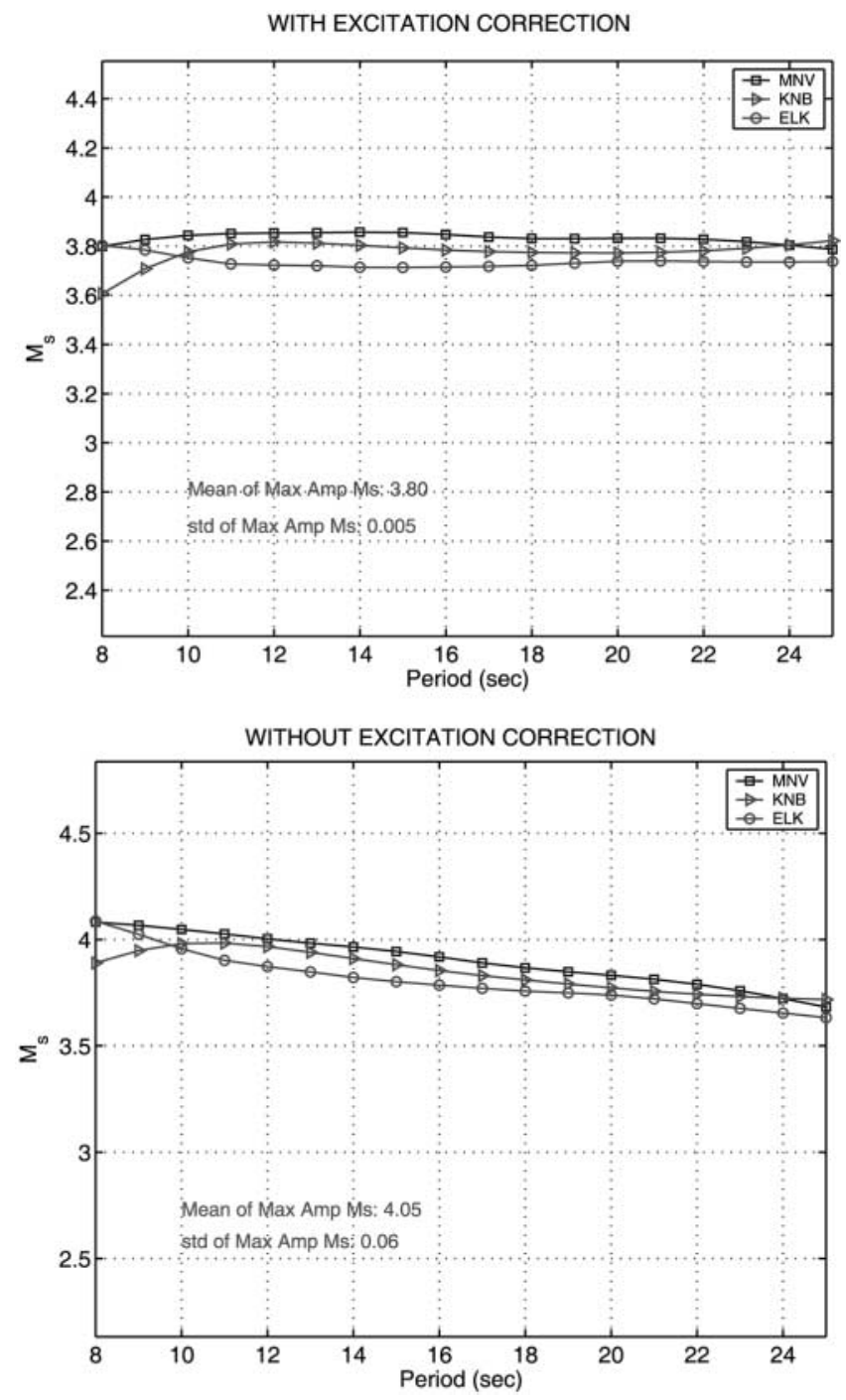

Figure 3. (Top) Example of the magnitude estimation technique $M_{\mathrm{s}}(\mathrm{VMAX})$ for the NTS explosion Cabra. The excitation correction $0.66 \log (20 / T)$ was applied to these magnitude estimates. (Bottom) Estimated $M_{\mathrm{s}}(\mathrm{VMAX})$ without applying an excitation correction. of the method, we have chosen to remain with one standard global correction as opposed to station-specific corrections. That could be considered in the future to further reduce variances in the estimates.

\section{Application}

We applied the Russell (2006) formula and our $M_{\mathrm{s}}(\mathrm{VMAX})$ technique to three different surface-wave datasets. For the first application of the formula, we estimated surface-wave magnitudes for several large earthquakes in the Mediterranean region of Europe. For the second and third applications, we estimated $M_{\mathrm{s}}(\mathrm{VMAX})$ for earthquakes and explosions in North America and Eurasia, respectively. And finally, we examined all the data in Eurasia to determine the performance of the $M_{\mathrm{s}}-m_{\mathrm{b}}$ discriminant when our magnitude estimation techniques are used.

\section{Mediterranean Region}

We applied the Russell (2006) formula and $M_{\mathrm{s}}$ (VMAX) measurement technique to earthquakes in the Mediterranean region to determine whether (1) we obtain consistent magnitudes at regional and teleseismic distances and (2) our $M_{\mathrm{s}}$ estimates match those obtained using the Vanĕk et al. (1962) and Rezapour and Pearce (1998) formulas.

Data. We developed a database of broadband recordings of 33 earthquakes that occurred in the Mediterranean region of Europe (Fig. 4 and Table 1). For this pilot study, we

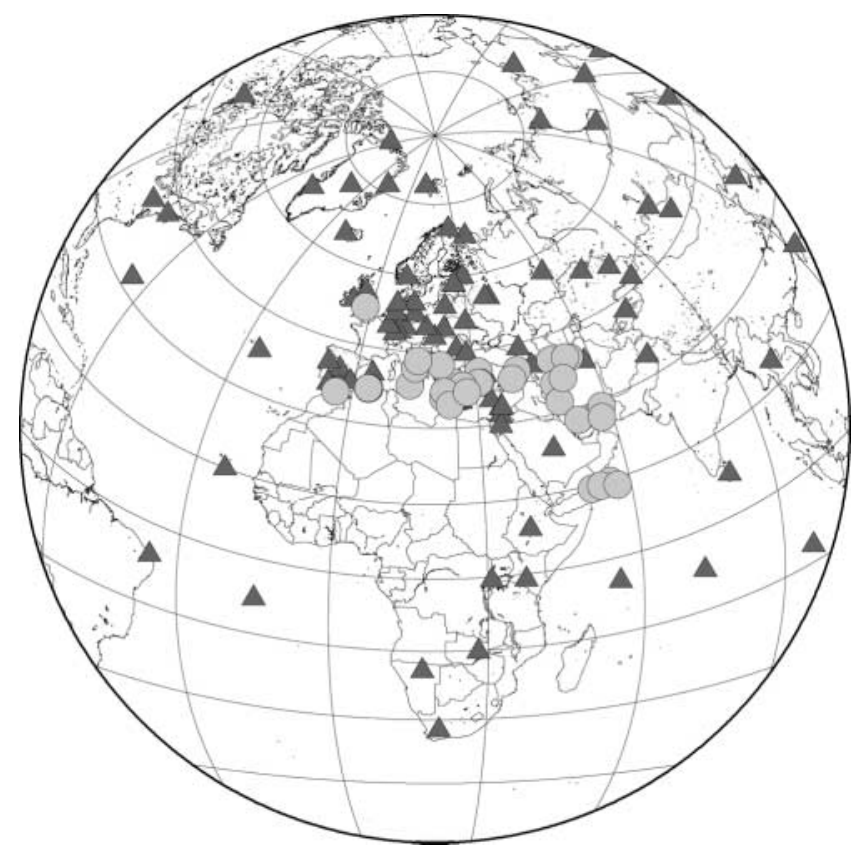

Figure 4. Test dataset of events in the Mediterranean region and stations used to test the Russell (2006) formula and $M_{\mathrm{s}}$ (VMAX) measurement technique. 
Table 1

Origin Information and $M_{\mathrm{s}}(\mathrm{VMAX})$ Test Results for Events in the Mediterranean Region

\begin{tabular}{|c|c|c|c|c|c|c|c|c|c|c|c|c|}
\hline Year & Month & Day & Hour & Minute & Second & Latitude & Longitude & Depth & $m_{\mathrm{b}}$ & $\begin{array}{c}M_{\mathrm{s}} \\
(\text { VMAX) }\end{array}$ & STD & No. \\
\hline 2004 & 08 & 04 & 3 & 1 & 07 & 36.92 & 27.76 & 10 & 5.5 & 5.21 & 0.02 & 44 \\
\hline 2004 & 08 & 11 & 15 & 48 & 21 & 38.38 & 39.25 & 10 & 5.5 & 5.54 & 0.17 & 41 \\
\hline 2004 & 05 & 28 & 0 & 38 & 44 & 36.25 & 51.62 & 17 & 6.3 & 6.34 & 0.20 & 58 \\
\hline 2004 & 05 & 28 & 12 & 38 & 46 & 36.27 & 51.57 & 26 & 6.2 & 6.30 & 0.19 & 46 \\
\hline 2004 & 03 & 01 & 0 & 36 & 02 & 37.22 & 22.26 & 31 & 5.5 & 4.45 & 0.19 & 36 \\
\hline 2004 & 03 & 17 & 5 & 21 & 01 & 34.59 & 23.48 & 25 & 6.1 & 5.71 & 0.2 & 42 \\
\hline 2004 & 03 & 25 & 19 & 30 & 50 & 39.93 & 40.86 & 10 & 5.5 & 5.30 & 0.19 & 45 \\
\hline 2004 & 01 & 14 & 16 & 58 & 51 & 27.7 & 52.31 & 33 & 5.4 & 4.34 & 0.21 & 34 \\
\hline 2004 & 01 & 28 & 9 & 6 & 06 & 26.89 & 57.59 & 10 & 5.4 & 4.57 & 0.23 & 38 \\
\hline 2004 & 02 & 13 & 0 & 41 & 40 & 13.69 & 57.25 & 10 & 5.5 & 4.86 & 0.24 & 35 \\
\hline 2004 & 02 & 24 & 2 & 27 & 46 & 35.14 & -4 & 0 & 6.4 & 6.3 & 0.22 & 42 \\
\hline 2003 & 12 & 26 & 3 & 6 & 17 & 28.86 & 58.32 & 33 & 5.4 & 5.31 & 0.17 & 39 \\
\hline 2003 & 05 & 24 & 1 & 46 & 06 & 14.43 & 53.81 & 10 & 5.8 & 5.49 & 0.23 & 47 \\
\hline 2003 & 04 & 10 & 0 & 40 & 15 & 38.21 & 26.87 & 10 & 5.6 & 5.41 & 0.18 & 33 \\
\hline 2003 & 05 & 27 & 17 & 11 & 29 & 36.94 & 3.58 & 8 & 5.7 & 5.21 & 0.25 & 49 \\
\hline 2003 & 03 & 29 & 17 & 42 & 18 & 43.26 & 15.49 & 33 & 5.5 & 5.14 & 0.24 & 34 \\
\hline 2002 & 10 & 31 & 10 & 32 & 59 & 41.73 & 14.89 & 10 & 5.6 & 5.45 & 0.18 & 29 \\
\hline 2002 & 09 & 06 & 1 & 21 & 28 & 38.37 & 13.72 & 10 & 6.1 & 5.63 & 0.2 & 26 \\
\hline 2002 & 09 & 25 & 22 & 28 & 16 & 32.09 & 49.23 & 33 & 5.5 & 5.00 & 0.22 & 28 \\
\hline 2002 & 08 & 13 & 8 & 37 & 23 & 14.75 & 55.85 & 10 & 5.8 & 5.49 & 0.26 & 49 \\
\hline 2002 & 09 & 01 & 17 & 14 & 59 & 14.25 & 51.81 & 10 & 5.6 & 5.80 & 0.25 & 28 \\
\hline 2002 & 04 & 24 & 10 & 51 & 51 & 42.43 & 21.51 & 10 & 5.5 & 5.42 & 0.19 & 23 \\
\hline 2002 & 06 & 22 & 2 & 58 & 21 & 35.63 & 49.05 & 10 & 6.5 & 6.33 & 0.18 & 59 \\
\hline 2002 & 04 & 17 & 8 & 47 & 22 & 27.61 & 56.76 & 33 & 5.4 & 4.62 & 0.20 & 39 \\
\hline 2002 & 02 & 03 & 7 & 11 & 28 & 38.57 & 31.27 & 5 & 6.5 & 6.38 & 0.22 & 65 \\
\hline 2002 & 02 & 03 & 9 & 26 & 43 & 38.63 & 30.9 & 10 & 5.8 & 5.48 & 0.22 & 68 \\
\hline 2001 & 07 & 26 & 0 & 21 & 38 & 39.06 & 24.34 & 10 & 6.3 & 6.66 & 0.18 & 12 \\
\hline 2001 & 06 & 10 & 1 & 52 & 08 & 39.84 & 53.89 & 34 & 5.6 & 5.00 & 0.25 & 21 \\
\hline 2000 & 11 & 25 & 18 & 9 & 11 & 40.25 & 49.95 & 50 & 6.3 & 6.55 & 0.16 & 48 \\
\hline 2000 & 12 & 06 & 17 & 11 & 06 & 39.57 & 54.8 & 30 & 7 & 7.3 & 0.28 & 69 \\
\hline 2000 & 12 & 15 & 16 & 44 & 45 & 38.61 & 31.06 & 10 & 5.8 & 5.62 & 0.13 & 15 \\
\hline 2000 & 05 & 24 & 5 & 40 & 38 & 36.04 & 22.01 & 33 & 5.7 & 5.57 & 0.16 & 51 \\
\hline 1999 & 11 & 12 & 16 & 57 & 20 & 40.76 & 31.16 & 10 & 7.2 & 7.35 & 0.25 & 55 \\
\hline
\end{tabular}

focused on larger events $\left(m_{\mathrm{b}}>5.4\right)$ with depths of $50 \mathrm{~km}$ or less. These restrictions ensured adequate SNRs for the surface waves recorded at regional and teleseismic distances. The data were acquired from the Incorporated Research Institutions for Seismology (IRIS) and consisted of global and regional networks in the study region. The data were all transformed from counts to displacement in nanometers by using the Seismic Analysis Code command "transfer" and the SEED response files. The data were decimated from their original sampling rates ( $>20$ samples/sec) to approximately $1 \mathrm{sample} / \mathrm{sec}$ for the surface-wave analysis. Down-sampling increases the analysis speed and eliminates digital filter problems associated with narrow-band filtering, as discussed in the electronic supplement of Russell (2006).

Results. Table 1 provides the $M_{\mathrm{s}}(\mathrm{VMAX})$ values obtained for the earthquakes in the Mediterranean region. Our first objective in this exercise was to determine whether there is a distance dependence in the formula and measurement technique. As mentioned in the introduction, previous research has been unsuccessful at finding a single, variable-period formula valid at both regional and teleseismic distances.

We performed a distance analysis on all 33 events of our test database similar to the one performed in the lower plot of Figure 2. To compare events of different magnitudes, we removed the mean magnitude from each event's analysis. Figure 5 shows the results, which include $1318 M_{\mathrm{s}}(\mathrm{VMAX})$ magnitude estimates from the events listed in Table 1. Our objective was to test the formula for a predominance of continental paths; thus, data are at distances less than 70 degrees. A linear regression of the mean-removed magnitude estimates with increasing distance shows a small (0.002 m.u. per degree) decrease in magnitudes. The standard deviation for the regression analysis is $0.21 \mathrm{~m}$.u. This suggests that if an event had an $M_{\mathrm{s}}(\mathrm{VMAX})$ magnitude estimate of 6.0 measured at a distance of 5 degrees, the magnitude estimated at a distance of 60 degrees would be $\sim 5.89$. This difference is well within the scatter typically observed for surface-wave magnitude estimates resulting from focal mechanisms and path effects.

Because $M_{\mathrm{s}}(\mathrm{VMAX})$ is a variable-period technique, we 


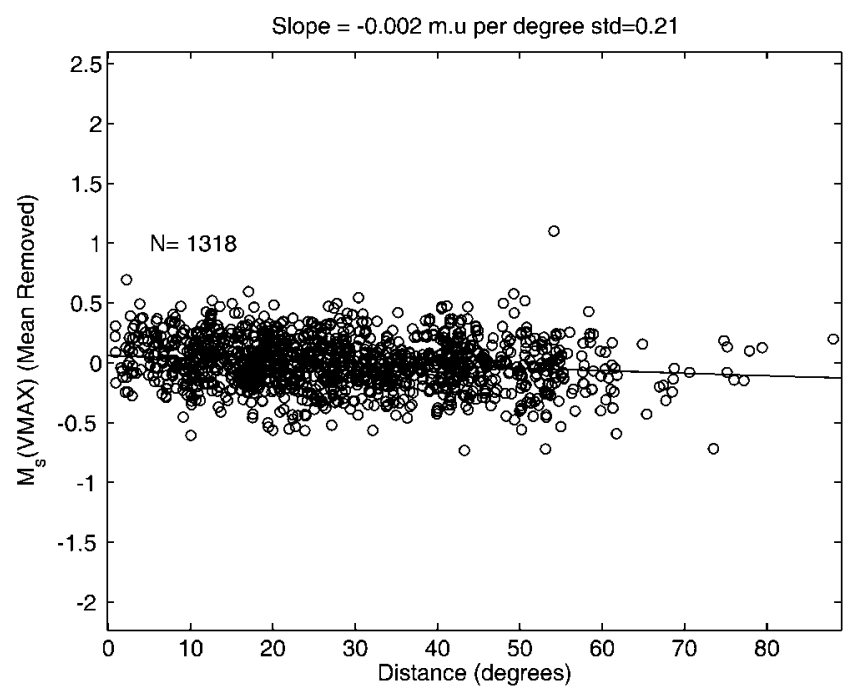

Figure 5. Regression of mean-removed $M_{\mathrm{s}}(\mathrm{VMAX})$ magnitude estimates for the 33 events in Table 1 with distance. There is a very small decrease in magnitude units (0.002 m.u. per degree) with increasing distance.

also examined the periods at which the estimates were formed (Fig. 6). There is a general increase in the number of measurements in each bin from shorter to longer periods. This increase is reassuring, because it is consistent with past studies which found that the best period range to measure $M_{\mathrm{s}}$ is between 17 and $23 \mathrm{sec}$.

We observe an edge effect associated with ending the surface-wave magnitude analysis at $25 \mathrm{sec}$. Two explanations exist for this behavior. Because of their spectral shape, the earthquakes will tend to select longer periods, especially when the events are deeper than the upper crust. In addition, because of the nature of surface-wave propagation, we would expect to see a general trend of longer-period measurements with increasing distances. This trend is related to the rapid attenuation of shorter-period amplitudes compared with the longer periods at longer epicentral distances. In Figure 6, we plotted the distances and periods at which the magnitudes were estimated. The plot shows that for the magnitudes estimated at periods of $10 \mathrm{sec}$ or less, the corresponding epicentral distances were less than 30 degrees. From 10 to $18 \mathrm{sec}$, we note a general increase in the cut-out distance from 30 to 60 degrees. For periods greater than $18 \mathrm{sec}$, note that the cutout distance continues to increase but is less constrained by the available data. The results in Figure 6 suggest that the formula is behaving as we intended. It also hints that the analysis could be improved by increasing the long-period limit to periods greater than $25 \mathrm{sec}$.

As a final step in the analysis of the events in Table 1, we compared our $M_{\mathrm{s}}(\mathrm{VMAX})$ estimates with magnitude estimates published by the U.S. Geological Survey (USGS) and the International Data Center (IDC) in Vienna, and with the $M_{\mathrm{w}}$ estimates obtained from Harvard's Centroid Moment Tensor (CMT) analysis. The results are shown in Figure 7. Note that the USGS uses the Vanĕk et al. (1962) formula, whereas the IDC uses the Rezapour and Pearce (1998) formula. We performed a fixed-slope (slope $=1$ ) regression of the $M_{\mathrm{s}}(\mathrm{VMAX})$ estimates against the results from the other organizations to determine the offset between the estimates. The results indicate that the $M_{\mathrm{s}}(\mathrm{VMAX})$ is -0.03 and 0.05 m.u. different than the Vaněk et al. (1962) and Rezapour and Pearce (1998) formulas, respectively. Differences of this size for all three comparisons are well within the scatter of the observations. Also, the bottom subplot of Figure 7 shows that the $M_{\mathrm{s}}(\mathrm{VMAX})$ and $M_{\mathrm{w}}$ estimates are approximately equal for $6.0<M_{\mathrm{w}}<7.2$.
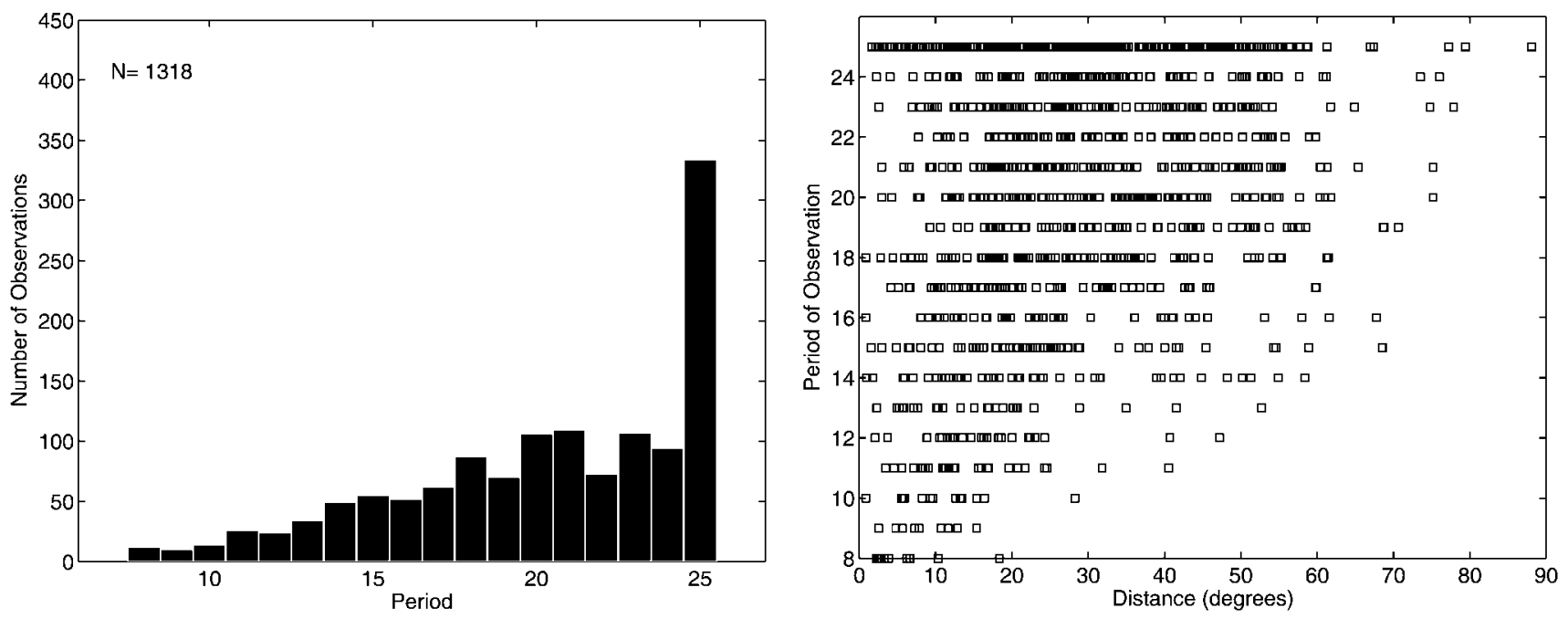

Figure 6. (Left) Bins showing the periods used to estimate the $M_{\mathrm{s}}(\mathrm{VMAX})$ magnitudes at 1318 different station-source pairs. (Right) Comparison of the periods of the $M_{\mathrm{s}}(\mathrm{VMAX})$ estimates compared with the epicentral distance. 

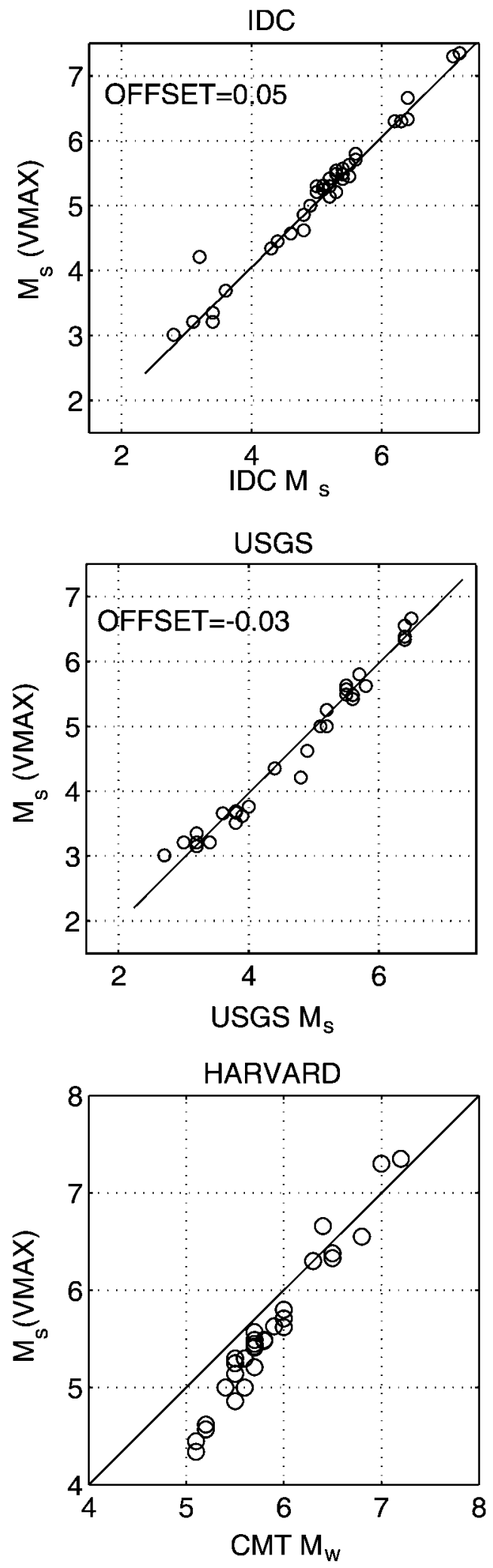

Figure 7. (Top) Fixed-slope (slope $=1$ ) regression of $M_{\mathrm{s}}(\mathrm{VMAX})$ network-average magnitudes versus the IDC $M_{\mathrm{s}}$ for the Mediterranean events. (Middle) Fixed-slope (slope $=1$ ) regression of $M_{\mathrm{s}}(\mathrm{VMAX})$ network-average magnitudes versus the USGS $M_{\mathrm{s}}$. (Bottom) Comparison of the $M_{\mathrm{s}}(\mathrm{VMAX})$ network-average magnitudes versus the Harvard CMT $M_{\mathrm{w}}$ values.
Nevada Test Site Earthquake and Explosion Discrimination

We next examined the performance of the Russell (2006) formula and $M_{\mathrm{s}}(\mathrm{VMAX})$ measurement technique on earthquake and explosion discrimination at the Nevada Test Site in the western United States.

Data. We developed a test dataset consisting of explosions and earthquakes in the western United States. The explosion data are digital broadband seismograms from NTS explosions recorded on two or more stations of the Lawrence Livermore Regional Seismic network (henceforth referred to as LNN). The LNN network consists of seismic stations at Landers, California (LAC); Mina, Nevada (MNV); Elko, Nevada (ELK); and Kanab, Utah (KNB); it has been in operation since the 1960s (Fig. 8). All data were converted from counts to displacement in nanometers using the Seismic Analysis Code (SAC) "transfer" command and pole-zero files.

We estimated $M_{\mathrm{s}}(\mathrm{VMAX})$ for NTS explosions that occurred between December 1968 and September 1992. Our primary focus was on the 198 NTS explosions that were detonated after August 1979, when digital data became available from the LNN stations. Of these 198 events, 133 had useable data, of which 65 either had no available LNN data, were plagued by untimely data dropouts and glitches, or were too small for measurable surface-wave energy. We also analyzed 21 explosions detonated prior to July 1979 that were digitized from analog records, to compare our new re-

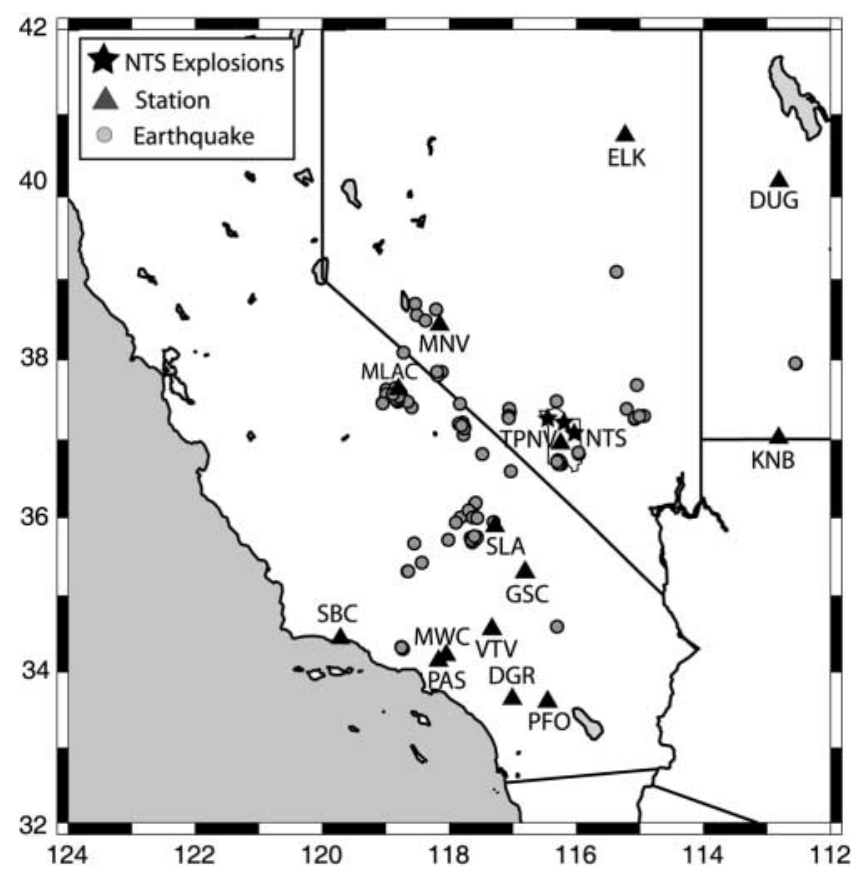

Figure 8. Test dataset consisting of NTS explosions recorded on the LNN dataset together with earthquakes in the western United States recorded on at least one LNN station and other regional networks. 
sults with previous $M_{\mathrm{s}}$ studies completed by Yacoub (1983) and Woods and Harkrider (1995). In addition to the explosion dataset, we also estimated the $M_{\mathrm{s}}$ and $m_{\mathrm{b}}$ magnitudes for 69 earthquakes whose locations are shown as gray circles in Figure 8. These events were recorded on various networks in the region; however, we ensured that at least one LNN station recorded the event. This requirement allowed us to measure an unbiased $m_{\mathrm{b}}$ using the Denny et al. $(1987,1989)$ $P n$ magnitude scale. Many of the $m_{\mathrm{b}}(P n)$ values used in this study were taken from Vergino and Mensing (1989) or Patton (2001).

Results. Table 2 provides the $M_{\mathrm{s}}(\mathrm{VMAX})$ estimates and standard deviations for the explosions on the Nevada Test Site. We compared the $M_{\mathrm{s}}(\mathrm{VMAX})$ measurements for the 154 explosions to the single 7-sec period measurements from our previous research. Figure 9 shows that the $M_{\mathrm{s}}(\mathrm{VMAX})$ explosion magnitudes are approximately 0.23 m.u. larger than the regionally calibrated Marshall and Basham $M_{\mathrm{s}}(7)$ estimates from Bonner et al. (2003). The slope of the best-fit line between the two datasets is approximately equal to 1 . The $M_{\mathrm{s}}(\mathrm{VMAX})$ methodology resulted in a $25 \%$ reduction of the variance for the explosions over the previous singleperiod techniques.

An important goal of our research is the ability to estimate near-regional $M_{\mathrm{s}}$ values for NTS events that can be calibrated to conventional $M_{\mathrm{s}}$ scales. Figure 10 shows the comparison of our $M_{\mathrm{s}}(\mathrm{VMAX})$ estimates, which are taken directly from the regional surface waves, to $M_{\mathrm{s}}$ measurements obtained from a modeling technique derived by Woods and Harkrider (1995) and to estimates from farregional/teleseismic data (Yacoub, 1983). Woods and Harkrider modeled the surface waves recorded at regional distances and then propagated the regional synthetics to distances of 40 degrees. At 40 degrees, their synthetics displayed significant 20 -sec surface-wave energy, and the authors used a modified von Seggern (1977) formula to measure $M_{\mathrm{s}}$ from the synthetics. We performed a fixed-slope (slope $=1$ ) linear regression to compare the $M_{\mathrm{s}}(\mathrm{VMAX})$ values with the Woods and Harkrider (1995) values and found a strong correlation. The offset shows that the $M_{\mathrm{s}}$ (VMAX) estimates are -0.11 m.u. lower than the Woods and Harkrider (1995) estimates.

We also compared the $M_{\mathrm{s}}(\mathrm{VMAX})$ estimates with teleseismic $M_{\mathrm{s}}$ estimates from Yacoub (1983). The results, shown in Figure 10, indicate that the two magnitude scales have similar scaling relationships, based on the fixed-slope regression analysis. In this case, the $M_{\mathrm{s}}(\mathrm{VMAX})$ estimates are offset from Yacoub's (1983) estimates by approximately +0.03 m.u.

Figure 11 shows the regression of the $M_{\mathrm{s}}(\mathrm{VMAX})$ versus the Denny et al. $(1987,1989) m_{\mathrm{b}}$ for both the earthquake (Table 3) and explosion (Table 2) populations in our test dataset. The best-fitting regression lines are plotted as solid lines, and the slope and intercepts for the lines are presented in the left subplot. The populations plotted in Figure 11 sug-
Table 2

$M_{\mathrm{s}}(\mathrm{VMAX})$ Test Results for Explosions on the Nevada Test Site

\begin{tabular}{|c|c|c|c|c|c|}
\hline Date & Name & $m_{\mathrm{b}}$ & $\begin{array}{c}M_{\mathrm{s}} \\
(\mathrm{VMAX})\end{array}$ & STD & No. \\
\hline 1968354 & Benham & 6.49 & 5.88 & 0.21 & 3 \\
\hline 1969302 & Calabash & 5.5 & 4.46 & 0.05 & 2 \\
\hline 1970085 & Handley & 6.57 & 5.78 & 0.04 & 4 \\
\hline 1970146 & Flask & 5.47 & 4.17 & 0.09 & 4 \\
\hline 1970351 & Carpetbag & 5.79 & 4.69 & 0.14 & 4 \\
\hline 1972265 & Osocurro & 5.6 & 4.47 & 0.06 & 3 \\
\hline 1972270 & Delphinium & 4.54 & 2.69 & 0.08 & 3 \\
\hline 1973116 & Starwort & 5.49 & 4.05 & 0.04 & 4 \\
\hline 1973157 & Alemendro & 6.23 & 5.33 & 0.19 & 3 \\
\hline 1974191 & Escabosa & 5.54 & 4.59 & 0.04 & 2 \\
\hline 1975059 & Topgallant & 5.7 & 4.44 & 0.05 & 4 \\
\hline 1975154 & Stilton & 6.03 & 4.77 & 0.06 & 4 \\
\hline 1975154 & Mizzen & 5.66 & 4.52 & 0.03 & 4 \\
\hline 1975170 & Mast & 6.24 & 5.18 & 0.12 & 4 \\
\hline 1975324 & Inlet & 6.01 & 5.03 & 0.13 & 4 \\
\hline 1975354 & Chiberta & 5.76 & 4.62 & 0.05 & 4 \\
\hline 1976035 & Keelson & 5.61 & 4.41 & 0.04 & 4 \\
\hline 1976035 & Esrom & 5.69 & 4.59 & 0.06 & 3 \\
\hline 1976045 & Cheshire & 6.13 & 5.18 & 0.07 & 4 \\
\hline 1976069 & Estuary & 6.09 & 5.25 & 0.13 & 4 \\
\hline 1976077 & Strait & 5.87 & 4.81 & 0.09 & 3 \\
\hline 1979215 & Burzet & 4.78 & 3.14 & 0.08 & 3 \\
\hline 1979220 & Offshore & 4.85 & 3.38 & 0.04 & 3 \\
\hline 1979241 & Nessel & 4.93 & 3.41 & 0.14 & 4 \\
\hline 1979249 & Hearts & 5.83 & 4.67 & 0.02 & 4 \\
\hline 1979269 & Sheepshead & 5.73 & 4.60 & 0.05 & 4 \\
\hline 1980059 & Tarko & 4.43 & 3.12 & 0.16 & 3 \\
\hline 1980094 & Liptauer & 4.9 & 3.15 & 0.28 & 4 \\
\hline 1980107 & Pyramid & 5.45 & 4.28 & 0.20 & 4 \\
\hline 1980117 & Colwick & 5.66 & 4.60 & 0.05 & 4 \\
\hline 1980123 & Canfield & 4.38 & 2.84 & 0.03 & 3 \\
\hline 1980164 & Kash & 5.61 & 4.67 & 0.04 & 3 \\
\hline 1980176 & Huron King & 4.2 & 2.45 & 0.10 & 3 \\
\hline 1980207 & Tafi & 5.8 & 4.70 & 0.05 & 4 \\
\hline 1980213 & Verdello & 4.12 & 2.67 & 0.14 & 2 \\
\hline 1980269 & Bonarda & 4.5 & 2.44 & 0.16 & 4 \\
\hline 1980298 & Dutchess & 4.43 & 3.00 & 0.12 & 4 \\
\hline 1980305 & Miners Iron & 4.65 & 3.34 & 0.12 & 4 \\
\hline 1980319 & Dauphin & 4.39 & 3.01 & 0.07 & 4 \\
\hline 1980352 & Serpa & 5.26 & 4.05 & 0.06 & 4 \\
\hline 1981015 & Baseball & 5.56 & 4.41 & 0.02 & 4 \\
\hline 1981149 & Aligote & 4.19 & 2.75 & 0.06 & 3 \\
\hline 1981157 & Harzer & 5.62 & 4.42 & 0.09 & 4 \\
\hline 1981191 & Niza & 4.18 & 2.58 & 0.06 & 4 \\
\hline 1981239 & Islay & 3.96 & 2.40 & 0.03 & 2 \\
\hline 1981247 & Trebbiano & 3.98 & 2.12 & 0.11 & 4 \\
\hline 1981274 & Paliza & 5.12 & 3.80 & 0.01 & 3 \\
\hline 1981315 & Tilci & 4.9 & 3.41 & 0.12 & 4 \\
\hline 1981316 & Rousanne & 5.38 & 4.17 & 0.05 & 4 \\
\hline 1981337 & Akavi & 4.7 & 3.23 & 0.18 & 4 \\
\hline 1981350 & Caboc & 4.53 & 2.80 & 0.10 & 4 \\
\hline 1982028 & Jornada & 5.76 & 4.65 & 0.04 & 4 \\
\hline 1982043 & Molbo & 5.48 & 4.42 & 0.15 & 4 \\
\hline 1982043 & Hosta & 5.76 & 4.45 & 0.06 & 4 \\
\hline 1982107 & Tenaja & 4.49 & 2.95 & 0.09 & 4 \\
\hline 1982115 & Gibne & 5.47 & 4.42 & 0.04 & 4 \\
\hline 1982126 & Kryddost & 4.19 & 2.48 & 0.06 & 2 \\
\hline 1982127 & Bouschet & 5.66 & 4.28 & 0.05 & 4 \\
\hline 1982167 & Kesti & 4.01 & 2.33 & 0.03 & 3 \\
\hline 1982175 & Nebbiolo & 5.73 & 4.57 & 0.09 & 4 \\
\hline
\end{tabular}

(continued) 
Table 2

Continued

\begin{tabular}{|c|c|c|c|c|c|}
\hline Date & Name & $m_{\mathrm{b}}$ & $\begin{array}{c}M_{\mathrm{s}} \\
(\text { VMAX) }\end{array}$ & STD & No. \\
\hline 1982210 & Monterey & 4.68 & 2.86 & 0.23 & 4 \\
\hline 1982217 & Atrisco & 5.82 & 4.71 & 0.07 & 4 \\
\hline 1982266 & Frisco & 4.9 & 3.49 & 0.13 & 3 \\
\hline 1982266 & Huron Landing & 4.88 & 3.35 & 0.11 & 3 \\
\hline 1982316 & Seyval & 4.18 & 2.35 & 0.01 & 2 \\
\hline 1982344 & Manteca & 4.72 & 3.10 & 0.10 & 4 \\
\hline 1983085 & Cabra & 5.36 & 4.12 & 0.04 & 3 \\
\hline 1983104 & Turquoise & 5.64 & 4.18 & 0.05 & 4 \\
\hline 1983112 & Armada & 4.15 & 2.33 & 0.25 & 3 \\
\hline 1983125 & Crowdie & 4.37 & 2.65 & 0.09 & 3 \\
\hline 1983146 & Fahada & 4.52 & 3.21 & 0.07 & 4 \\
\hline 1983160 & Danablu & 4.73 & 2.80 & 0.02 & 2 \\
\hline 1983215 & Laban & 4.48 & 2.59 & 0.14 & 2 \\
\hline 1983223 & Sabado & 4.17 & 2.46 & 0.18 & 3 \\
\hline 1983239 & Jarlsberg & 3.87 & 2.27 & 0.20 & 2 \\
\hline 1983244 & Chancellor & 5.52 & 4.22 & 0.11 & 3 \\
\hline 1983264 & MidniteZ & 4.04 & 2.66 & 0.21 & 4 \\
\hline 1983265 & Techado & 4.2 & 2.48 & 0.08 & 4 \\
\hline 1983350 & Romano & 4.97 & 3.77 & 0.07 & 3 \\
\hline 1984031 & Gorbea & 4.51 & 2.79 & 0.11 & 4 \\
\hline 1984061 & Tortugas & 5.82 & 4.51 & 0.03 & 3 \\
\hline 1984091 & Agrini & 4.35 & 2.60 & 0.15 & 2 \\
\hline 1984122 & Mundo & 5.47 & 4.38 & 0.04 & 2 \\
\hline 1984152 & Caprock & 5.61 & 4.51 & 0.09 & 3 \\
\hline 1984207 & Kappeli & 5.62 & 4.40 & 0.10 & 3 \\
\hline 1984215 & Correo & 4.57 & 2.91 & 0.06 & 4 \\
\hline 1984243 & Dolcetto & 4.49 & 3.15 & 0.11 & 3 \\
\hline 1984257 & Breton & 4.98 & 3.64 & 0.05 & 4 \\
\hline 1984276 & Vermejo & 4.28 & 2.62 & 0.03 & 2 \\
\hline 1984344 & Egmont & 5.51 & 4.32 & 0.12 & 4 \\
\hline 1984350 & Tierra & 5.64 & 4.36 & 0.12 & 4 \\
\hline 1985074 & Vaughn & 4.42 & 3.09 & 0.07 & 3 \\
\hline 1985096 & Misty Rain & 4.7 & 3.44 & 0.08 & 4 \\
\hline 1985122 & Towanda & 5.63 & 4.48 & 0.07 & 4 \\
\hline 1985163 & Salut & 5.62 & 4.49 & 0.03 & 4 \\
\hline 1985206 & Serena & 5.48 & 4.48 & 0.18 & 3 \\
\hline 1985270 & Ponil & 4.49 & 3.15 & 0.10 & 4 \\
\hline 1985282 & Diamond Beech & 4.01 & 2.42 & 0.09 & 4 \\
\hline 1985289 & Roquefort & 4.62 & 3.07 & 0.06 & 4 \\
\hline 1985339 & Kinibito & 5.6 & 4.26 & 0.06 & 3 \\
\hline 1985362 & Goldstone & 5.45 & 4.28 & 0.01 & 4 \\
\hline 1986081 & Glencoe & 5.41 & 3.74 & 0.09 & 3 \\
\hline 1986100 & Mighty Oak & 4.93 & 3.52 & 0.05 & 2 \\
\hline 1986112 & Jefferson & 5.48 & 4.42 & 0.14 & 3 \\
\hline 1986141 & Panamint & 3.78 & 2.33 & 0.04 & 3 \\
\hline 1986156 & Tajo & 5.29 & 4.18 & 0.00 & 1 \\
\hline 1986176 & Darwin & 5.58 & 4.41 & 0.05 & 3 \\
\hline 1986198 & Cybar & 5.57 & 4.51 & 0.02 & 3 \\
\hline 1986205 & Cornucopia & 4.3 & 2.61 & 0.08 & 3 \\
\hline 1986247 & Galveston & 3.71 & 2.50 & 0.08 & 2 \\
\hline 1986273 & Labquark & 5.54 & 4.50 & 0.04 & 2 \\
\hline 1986289 & Belmont & 5.56 & 4.52 & 0.05 & 3 \\
\hline 1986318 & Gascon & 5.58 & 4.43 & 0.00 & 1 \\
\hline 1986347 & Bodie & 5.52 & 4.55 & 0.00 & 1 \\
\hline 1987042 & Tornero & 4.24 & 2.40 & 0.07 & 3 \\
\hline 1987077 & Middle Note & 4.22 & 2.67 & 0.01 & 2 \\
\hline 1987108 & Delamar & 5.51 & 4.40 & 0.07 & 3 \\
\hline 1987120 & Hardin & 5.54 & 4.53 & 0.07 & 3 \\
\hline 1987169 & Brie & 4.15 & 2.38 & 0.04 & 3 \\
\hline 1987225 & Tahoka & 5.72 & 4.58 & 0.00 & 1 \\
\hline
\end{tabular}

(continued)
Table 2

Continued

\begin{tabular}{clcccc}
\hline Date & Name & $m_{\mathrm{b}}$ & $\begin{array}{c}M_{\mathrm{s}} \\
\text { (VMAX) }\end{array}$ & STD & No. \\
\hline 1987267 & Lockney & 5.61 & 4.60 & 0.07 & 2 \\
1988046 & Kernville & 5.48 & 4.30 & 0.11 & 3 \\
1988134 & Schellbourne & 4.77 & 3.36 & 0.03 & 3 \\
1988142 & Laredo & 4.27 & 2.75 & 0.10 & 4 \\
1988154 & Comstock & 5.58 & 4.34 & 0.02 & 2 \\
1988189 & Alamo & 5.78 & 4.64 & 0.19 & 3 \\
1988230 & Kearsarge & 5.64 & 4.41 & 0.10 & 4 \\
1988243 & Bullfrog & 5.04 & 3.57 & 0.06 & 4 \\
1988287 & Dalhart & 5.67 & 4.59 & 0.05 & 4 \\
1988345 & Misty Echo & 4.79 & 3.48 & 0.00 & 1 \\
1989041 & Texarkana & 5.32 & 3.99 & 0.02 & 3 \\
1989055 & Kawich-Red & 4.41 & 2.47 & 0.14 & 3 \\
1989068 & Ingot & 4.86 & 3.52 & 0.07 & 3 \\
1989135 & Palisade-1 & 4.55 & 2.71 & 0.07 & 3 \\
1989146 & Tulia & 3.7 & 2.23 & 0.12 & 3 \\
1989173 & Contact & 5.43 & 4.26 & 0.08 & 3 \\
1989178 & Amarillo & 5.03 & 3.58 & 0.21 & 3 \\
1989257 & Disko Elm & 4.04 & 2.40 & 0.17 & 4 \\
1989304 & Hornitos & 5.83 & 4.40 & 0.09 & 4 \\
1989342 & Barnwell & 5.56 & 4.19 & 0.16 & 4 \\
1990069 & Metropolis & 5.16 & 3.66 & 0.03 & 4 \\
1990164 & Bullion & 5.96 & 4.76 & 0.06 & 4 \\
1990172 & Austin & 4.21 & 2.72 & 0.12 & 4 \\
1990206 & Mineral Quarry & 4.53 & 3.23 & 0.18 & 4 \\
1990318 & Houston & 5.46 & 4.13 & 0.05 & 4 \\
1991067 & Coso-Bronze & 4.51 & 2.91 & 0.16 & 3 \\
1991094 & Bexar & 5.65 & 4.36 & 0.04 & 3 \\
1991257 & Hoya & 5.69 & 4.47 & 0.04 & 3 \\
1991262 & Distant Zenith & 4.09 & 2.62 & 0.12 & 3 \\
1991291 & Lubbock & 5.16 & 3.57 & 0.10 & 3 \\
1991330 & Bristol & 4.79 & 3.35 & 0.17 & 3 \\
1992086 & Junction & 5.81 & 4.16 & 0.31 & 3 \\
1992175 & Galena-Yellow & 4.13 & 2.52 & 0.06 & 3 \\
1992262 & Hunters Trophy & 4.16 & 2.59 & 0.12 & 3 \\
\hline & & & & &
\end{tabular}

gest that $M_{\mathrm{s}}$ and $m_{\mathrm{b}}$ will be fitted well by linear regressions, with approximately equal slopes assumed for the earthquake and explosion populations. Although we did observe slightly different slopes in the regression analyses for the two populations, we believe that this is due to inadequate sampling of earthquakes at $m_{\mathrm{b}}$ magnitudes greater than 5.2. Our dataset does not present any evidence that the two populations are converging at smaller magnitudes, although other $M_{\mathrm{s}}-$ $m_{\mathrm{b}}$ studies (Stevens and McLaughlin, 2001) suggest that convergence does occur. The classification equation based on the parallel-slope assumption becomes:

$$
d=M_{\mathrm{s}}(\mathrm{VMAX})-1.3 m_{\mathrm{b}},
$$

where $d$ is the decision value. We chose to use the explosion slope because we believe that it is better constrained with the available data, and synthetic studies suggest (Bonner and Herrmann, 2004) that it does not change with increasing magnitude. If $d<-2.30$, the event will reside in the explosion population. We note that this does not require the event to be a nuclear explosion, because additional testing 


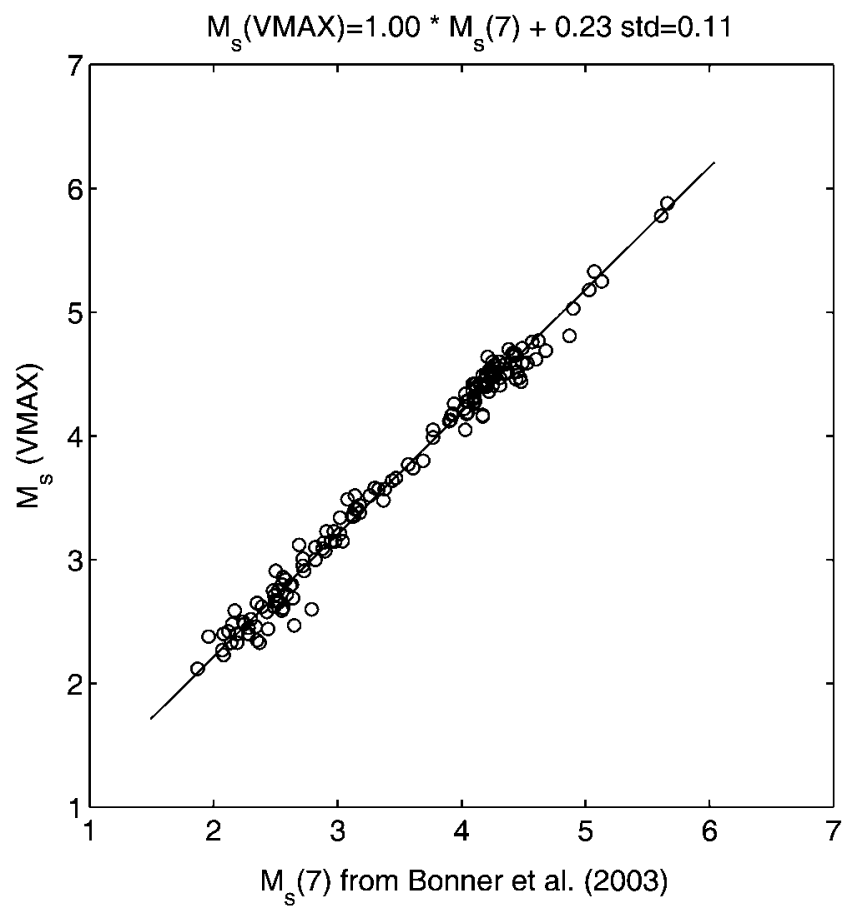

Figure 9. $M_{\mathrm{s}}(\mathrm{VMAX})$ magnitude estimates compared with 7-sec estimates based on a regionally calibrated Marshall and Basham formula. The $M_{\mathrm{s}}$ (VMAX) estimates result in a $25 \%$ reduction in variance as compared with the 7 -sec estimates and are 0.25 m.u. larger.

is needed to ensure the event is shallow enough to be a candidate explosion. If $d>2.30$, the event falls into the earthquake classification. We misclassified two earthquakes in the explosion population. In our previous studies based on 7-sec data (Bonner et al., 2003), we misclassified four earthquakes as explosions.

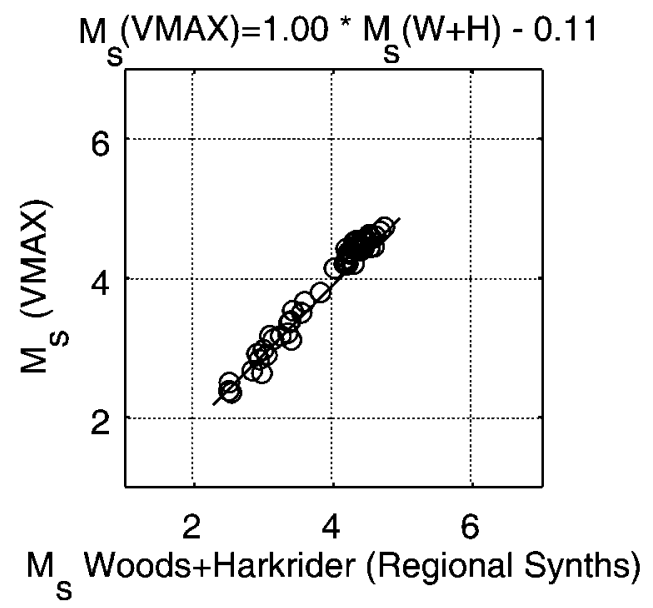

Lop Nor Test Site Earthquake and Explosion Discrimination

In our third application of the Russell (2006) formula and $M_{\mathrm{s}}(\mathrm{VMAX})$ measurement technique, we examined earthquake and explosion discrimination at the Lop Nor nuclear test site in China.

Data. We developed a test dataset consisting of nine nuclear explosions and 38 earthquakes that occurred within 5 degrees of the Lop Nor test site. The broadband verticalcomponent data were acquired from IRIS and consisted of global and regional networks in the study region (Fig. 12). The data were all transformed from counts to displacement in nanometers using the SAC command "transfer" and SEED response files. The data were decimated from their original sampling rates ( $>20$ samples/sec) to approximately 1 sam$\mathrm{ple} / \mathrm{sec}$ for the surface-wave analysis. We do not have access to a calibrated body-wave magnitude scale for the Lop Nor region; thus, we have used the USGS-estimated $m_{\mathrm{b}}$ values in our discrimination analysis.

Results. Table 4 provides the $M_{\mathrm{s}}(\mathrm{VMAX})$ estimates and standard deviations for the explosions on the Lop Nor test site. The results for the earthquakes near the Lop Nor test site are compiled in Table 5. As shown in Figure 13, we regressed the $M_{\mathrm{s}}(\mathrm{VMAX})$ versus the USGS $m_{\mathrm{b}}$ for both the earthquake (Table 5) and explosion (Table 4) populations in our test dataset. The best-fitting regression lines are plotted as solid lines. The slope and intercepts for the lines are presented in the left subplot.

The slopes for the earthquake and explosion data were 1.0 and 1.2, respectively. Again, there is no evidence suggesting that the populations are converging at smaller magnitudes. We used the slope for the explosions to compute a

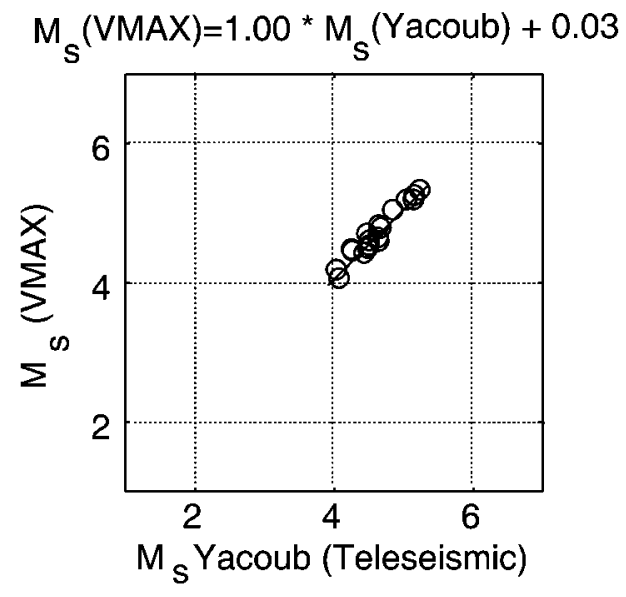

Figure 10. Fixed (slope $=1$ ) regressions of $M_{\mathrm{s}}(\mathrm{VMAX})$ versus Woods and Harkrider (1995) (left) and Yacoub (1983) (right). The best-fitting regression line, with a fixed slope $=1.0$, is given by the solid line running through the data points, and the offset is referenced in the equation above each plot. 

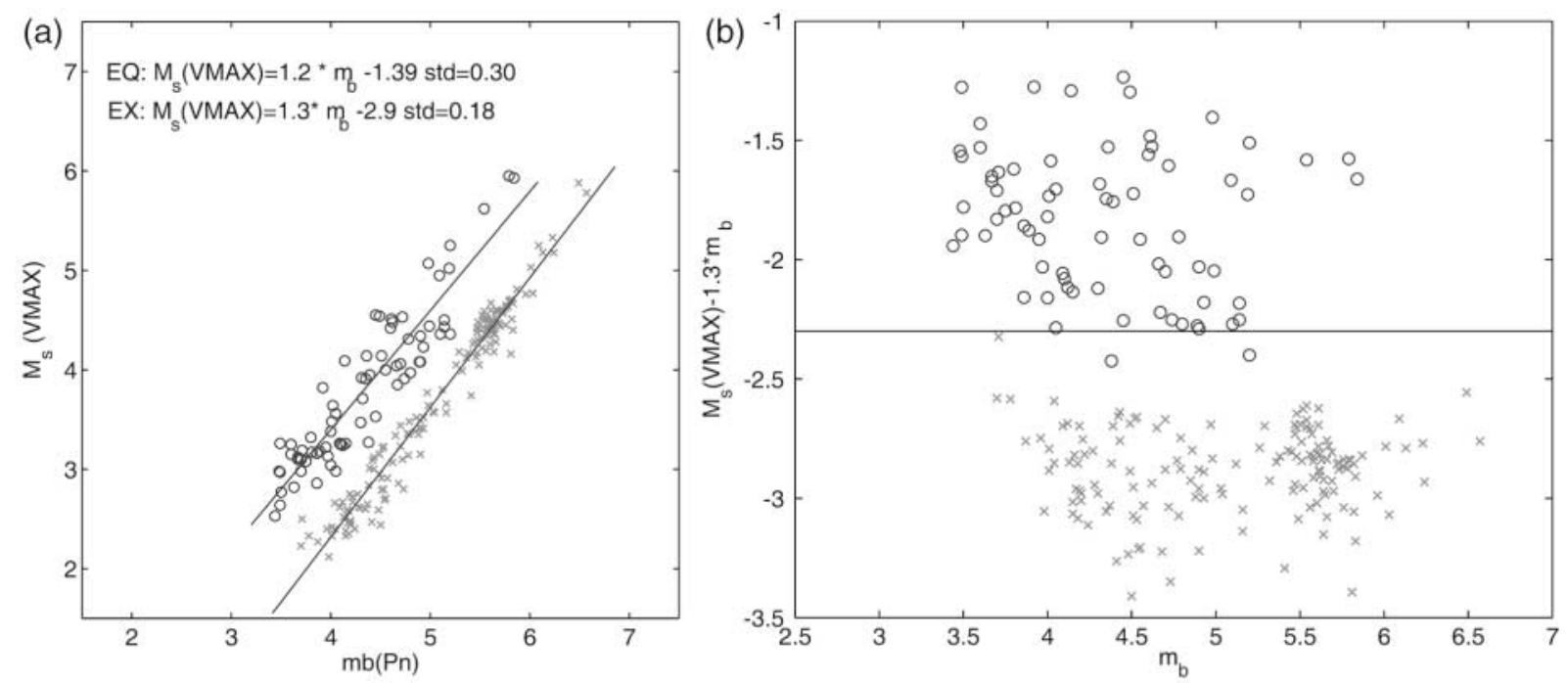

Explosions $\mathrm{x}$

Earthquakes o

Figure 11. Discrimination results for $M_{\mathrm{s}}(\mathrm{VMAX})$ at the Nevada Test Site. (a) $M_{\mathrm{s}}$ (VMAX) versus $m_{\mathrm{b}}$ for western United States earthquakes and nuclear explosions. (b) Linear discrimination of the two datasets showing the decision line for classifying an event as a possible nuclear explosion. If $d=M_{\mathrm{s}}(\mathrm{VMAX})-1.3 m_{\mathrm{b}}$ is less than -2.30 , the event may be an explosion, and additional analysis will be required to prove the event is not a deep and/or anomalous earthquake.

linear discriminant analysis. As a result, we developed the following classification equation:

$$
d=M_{\mathrm{s}}(\mathrm{VMAX})-1.2 m_{\mathrm{b}}
$$

where $d$ is the decision value. If $d<-2.6$, the event will reside in the explosion population and requires additional processing prior to being classified as a candidate explosion. If $d>-2.6$, the event falls into the earthquake classification. No Lop Nor explosions or earthquakes were misclassified using the VMAX magnitude estimation technique with the Russell (2006) surface-wave magnitude scale. However, we have fewer events for this region than we did for the NTS comparison.

\section{Discussion}

There is a general disagreement among researchers in the nuclear monitoring community as to how well the $M_{\mathrm{s}}-m_{\mathrm{b}}$ discriminant performs at small-to-intermediate bodywave magnitudes. Some researchers believe that the available $M_{\mathrm{s}}-m_{\mathrm{b}}$ datasets suggest that the two populations converge at smaller magnitudes (e.g., Stevens and McLaughlin, 2001). These researchers believe that the population convergence is caused by earthquake and explosion sources that become phenomenologically similar at smaller magnitudes. Lambert and Alexander (1971) determined that the earthquake and explosion populations at the Nevada Test Site are characterized by parallel $M_{\mathrm{s}}$ versus $m_{\mathrm{b}}$ curves, with slopes of 1 and a difference of 0.82 m.u. based on linear regression fits. Alexander (2002; personal comm., 2004) suggests that any convergence at the smaller magnitudes is related to depth and not the phenomenology behind explosion and earthquake sources.

To determine whether depth or source phenomenology is responsible for converging $M_{\mathrm{s}}-m_{\mathrm{b}}$ behavior at smaller magnitudes, we pooled all of the Eurasian earthquake (Tables 1 and 5) $M_{\mathrm{s}}(\mathrm{VMAX})$ estimates. We also calculated $M_{\mathrm{s}}(\mathrm{VMAX})$ for 11 additional nuclear explosions in Eurasia (Table 6) and combined them with the Lop Nor explosions from Table 4. Figure 14 shows the $M_{\mathrm{s}}(\mathrm{VMAX})$ estimates from all these data plotted versus the USGS $m_{\mathrm{b}}$.

Because of corner frequency effects for earthquakes and $m_{\mathrm{b}}$ measurement procedures, there should be a change in slope for regressed $M_{\mathrm{s}}(\mathrm{VMAX})$ versus $m_{\mathrm{b}}$ near $m_{\mathrm{b}} 5$ (Nuttli, 1983). As shown in Figure 14, the slope for the best-fit regressions above $m_{\mathrm{b}} 5$ is 1.46 with a standard deviation of 0.21 m.u. The slope for the regressions below $m_{\mathrm{b}} 5$ is 0.94 , which is similar to the slope determined for the observed explosion data (1.04). With the current dataset, we can not rule out the possibility that a single line with slope equal to 1.54 can fit all of the earthquake data. In fact, the correlation coefficients for single-line or two-line fits are essentially the same $\left(R^{2}>0.85\right)$. If the earthquake data were fit with a single line, we would see convergence of the populations near $m_{\mathrm{b}} 3.5$, which agrees with Stevens and McLaughlin (2001).

If we focus on the two-line case, however, the slopes 
Table 3

Origin Information and $M_{\mathrm{s}}(\mathrm{VMAX})$ Test Results for Earthquakes in the Nevada Test Site Region

\begin{tabular}{|c|c|c|c|c|c|c|c|c|c|c|c|c|}
\hline Year & Month & Day & Hour & Minute & Second & Latitute & Longitude & Depth & $m_{\mathrm{b}}$ & $\begin{array}{c}M_{\mathrm{s}} \\
(\mathrm{VMAX})\end{array}$ & STD & No. \\
\hline 1979 & 08 & 12 & 11 & 31 & 19 & 37.26 & -115.08 & 5.0 & 3.18 & 2.67 & 0.12 & 3 \\
\hline 1979 & 12 & 25 & 00 & 0 & 00 & 37.27 & -117.06 & 5.0 & 3.67 & 3.12 & 0.07 & 4 \\
\hline 1980 & 01 & 15 & 20 & 28 & 22 & 36.18 & -117.60 & 8.0 & 3.63 & 2.82 & 0.12 & 3 \\
\hline 1980 & 02 & 25 & 23 & 43 & 32 & 36.20 & -117.58 & 5.0 & 3.86 & 2.86 & 0.18 & 4 \\
\hline 1980 & 05 & 27 & 14 & 50 & 57 & 37.48 & -118.81 & 13.0 & 5.79 & 5.95 & 0.31 & 4 \\
\hline 1981 & 12 & 01 & 16 & 18 & 50 & 38.62 & -118.19 & 11.0 & 4.02 & 3.64 & 0.14 & 2 \\
\hline 1981 & 12 & 19 & 20 & 56 & 52 & 38.63 & -118.21 & 17.0 & 4.12 & 3.24 & 0.12 & 3 \\
\hline 1982 & 01 & 24 & 15 & 44 & 07 & 37.45 & -117.83 & 5.0 & 4.09 & 3.26 & 0.09 & 4 \\
\hline 1982 & 03 & 16 & 08 & 47 & 00 & 36.60 & -117.03 & 6.0 & 3.48 & 2.98 & 0.06 & 3 \\
\hline 1982 & 05 & 12 & 19 & 29 & 24 & 37.27 & -115.08 & 10.0 & 3.49 & 2.97 & 0.08 & 4 \\
\hline 1982 & 07 & 06 & 02 & 10 & 43 & 37.69 & -115.05 & 3.0 & 4.3 & 3.47 & 0.05 & 3 \\
\hline 1982 & 09 & 24 & 07 & 40 & 24 & 37.85 & -118.12 & 5.0 & 4.99 & 4.44 & 0.16 & 4 \\
\hline 1983 & 06 & 04 & 11 & 37 & 40 & 37.39 & -115.21 & 6.0 & 3.44 & 2.53 & 0.16 & 4 \\
\hline 1984 & 08 & 02 & 11 & 1 & 34 & 37.30 & -114.94 & 5.0 & 3.49 & 2.64 & 0.13 & 4 \\
\hline 1984 & 11 & 23 & 18 & 8 & 25 & 37.48 & -118.66 & 5.0 & 5.54 & 5.62 & 0.20 & 4 \\
\hline 1985 & 12 & 10 & 06 & 10 & 25 & 37.30 & -115.01 & 5.0 & 3.7 & 3.10 & 0.07 & 2 \\
\hline 1992 & 06 & 29 & 10 & 31 & 02 & 36.69 & -116.24 & 5.0 & 4.66 & 4.04 & 0.05 & 2 \\
\hline 1992 & 06 & 29 & 15 & 52 & 39 & 36.71 & -116.29 & 7.9 & 3.89 & 3.18 & 0.31 & 2 \\
\hline 1992 & 06 & 29 & 17 & 1 & 16 & 36.74 & -116.29 & 7.6 & 3.81 & 3.17 & 0.03 & 2 \\
\hline 1992 & 06 & 30 & 16 & 6 & 24 & 36.72 & -116.26 & 5.0 & 3.5 & 2.77 & 0.47 & 2 \\
\hline 1992 & 07 & 05 & 06 & 54 & 12 & 36.69 & -116.28 & 5.0 & 4.38 & 3.27 & 0.27 & 2 \\
\hline 1993 & 05 & 17 & 23 & 20 & 49 & 37.17 & -117.78 & 6.0 & 5.84 & 5.93 & 0.35 & 3 \\
\hline 1993 & 05 & 18 & 01 & 3 & 06 & 37.15 & -117.76 & 2.0 & 4.9 & 4.08 & 0.29 & 4 \\
\hline 1993 & 05 & 18 & 23 & 48 & 53 & 37.06 & -117.78 & 3.0 & 4.93 & 4.23 & 0.22 & 4 \\
\hline 1993 & 05 & 20 & 20 & 14 & 14 & 36.10 & -117.70 & 0.0 & 4.32 & 3.71 & 0.14 & 2 \\
\hline 1995 & 06 & 26 & 08 & 40 & 27 & 34.31 & -118.73 & 7.0 & 4.72 & 4.53 & 0.24 & 9 \\
\hline 1995 & 08 & 17 & 22 & 39 & 58 & 35.75 & -117.66 & 4.7 & 5.09 & 4.95 & 0.20 & 12 \\
\hline 1995 & 08 & 30 & 15 & 54 & 22 & 35.73 & -117.59 & 3.4 & 3.67 & 3.10 & 0.23 & 9 \\
\hline 1995 & 09 & 20 & 23 & 27 & 36 & 35.69 & -117.64 & 5.0 & 4.98 & 5.07 & 0.2 & 12 \\
\hline 1995 & 09 & 22 & 14 & 47 & 22 & 38.70 & -118.54 & 17.9 & 4.80 & 3.97 & 0.13 & 6 \\
\hline 1996 & 01 & 07 & 14 & 32 & 53 & 35.72 & -117.65 & 2.1 & 4.45 & 4.55 & 0.19 & 13 \\
\hline 1996 & 01 & 08 & 08 & 57 & 10 & 35.76 & -117.57 & 0.7 & 3.75 & 3.08 & 0.17 & 9 \\
\hline 1996 & 01 & 08 & 10 & 52 & 29 & 35.75 & -117.57 & 5.1 & 3.92 & 3.82 & 0.29 & 10 \\
\hline 1996 & 04 & 02 & 01 & 50 & 09 & 37.60 & -118.91 & 7.1 & 4.05 & 3.56 & 0.14 & 8 \\
\hline 1996 & 05 & 01 & 19 & 49 & 56 & 34.33 & -118.75 & 22.3 & 4.00 & 3.38 & 0.23 & 10 \\
\hline 1996 & 06 & 02 & 07 & 0 & 06 & 39.09 & -115.37 & 63.4 & 3.49 & 3.26 & 0.16 & 7 \\
\hline 1996 & 11 & 27 & 20 & 17 & 24 & 36.01 & -117.62 & 5.0 & 5.14 & 4.50 & 0.15 & 13 \\
\hline 1997 & 04 & 14 & 11 & 20 & 54 & 38.09 & -118.72 & 0.0 & 4.00 & 3.04 & 0.18 & 7 \\
\hline 1997 & 05 & 06 & 19 & 12 & 53 & 35.43 & -118.43 & 11.0 & 3.70 & 2.98 & 0.15 & 8 \\
\hline 1997 & 07 & 03 & 17 & 49 & 36 & 35.77 & -117.61 & 0.3 & 3.97 & 3.13 & 0.17 & 11 \\
\hline 1997 & 08 & 21 & 16 & 11 & 24 & 38.55 & -118.50 & 5.1 & 4.55 & 4.00 & 0.14 & 8 \\
\hline 1997 & 08 & 21 & 16 & 36 & 47 & 38.56 & -118.51 & 9.4 & 4.67 & 3.85 & 0.14 & 8 \\
\hline 1997 & 11 & 02 & 08 & 51 & 54 & 37.81 & -118.18 & 5.5 & 5.19 & 5.02 & 0.19 & 7 \\
\hline 1997 & 11 & 02 & 15 & 3 & 04 & 37.85 & -118.19 & 5.0 & 4.51 & 4.14 & 0.2 & 7 \\
\hline 1997 & 11 & 05 & 23 & 0 & 08 & 37.20 & -117.85 & 4.7 & 4.45 & 3.53 & 0.04 & 7 \\
\hline 1997 & 11 & 15 & 06 & 0 & 20 & 37.18 & -117.81 & 5.0 & 4.61 & 4.51 & 0.10 & 8 \\
\hline 1997 & 11 & 22 & 12 & 6 & 57 & 37.63 & -118.96 & 8.4 & 4.14 & 4.09 & 0.16 & 8 \\
\hline 1997 & 11 & 22 & 17 & 20 & 37 & 37.64 & -118.99 & 7.0 & 4.49 & 4.54 & 0.18 & 7 \\
\hline 1997 & 11 & 22 & 18 & 11 & 01 & 37.63 & -118.99 & 8.1 & 4.35 & 3.91 & 0.25 & 8 \\
\hline 1997 & 11 & 30 & 21 & 17 & 07 & 37.57 & -118.99 & 7.1 & 4.62 & 4.48 & 0.22 & 7 \\
\hline 1997 & 12 & 31 & 20 & 36 & 49 & 37.65 & -118.85 & 6.6 & 4.78 & 4.31 & 0.10 & 6 \\
\hline 1998 & 03 & 06 & 07 & 36 & 34 & 36.01 & -117.63 & 2.1 & 4.15 & 3.26 & 0.10 & 6 \\
\hline 1998 & 03 & 07 & 00 & 36 & 46 & 36.00 & -117.56 & 1.7 & 4.74 & 3.91 & 0.19 & 8 \\
\hline 1998 & 04 & 24 & 16 & 17 & 27 & 38.49 & -118.38 & 9.8 & 4.01 & 3.48 & 0.13 & 7 \\
\hline 1998 & 06 & 09 & 05 & 24 & 41 & 37.59 & -118.81 & 6.7 & 5.14 & 4.43 & 0.19 & 5 \\
\hline 1998 & 06 & 18 & 11 & 0 & 41 & 37.96 & -112.55 & 2.1 & 3.80 & 3.32 & 0.14 & 6 \\
\hline 1998 & 07 & 02 & 03 & 39 & 51 & 36.82 & -117.48 & 7.1 & 5.20 & 4.36 & 0.02 & 4 \\
\hline 1998 & 07 & 15 & 04 & 53 & 21 & 37.55 & -118.81 & 16.9 & 4.90 & 4.34 & 0.17 & 8 \\
\hline 1999 & 01 & 27 & 10 & 44 & 23 & 36.84 & -115.97 & 0.5 & 4.36 & 4.14 & 0.24 & 7 \\
\hline 1999 & 05 & 15 & 13 & 22 & 12 & 37.49 & -118.81 & 5.8 & 5.20 & 5.25 & 0.21 & 8 \\
\hline
\end{tabular}


Table 3

Continued

\begin{tabular}{|c|c|c|c|c|c|c|c|c|c|c|c|c|}
\hline Year & Month & Day & Hour & Minute & Second & Latitute & Longitude & Depth & $m_{\mathrm{b}}$ & $\begin{array}{c}M_{\mathrm{s}} \\
(\mathrm{VMAX})\end{array}$ & STD & No. \\
\hline 1999 & 05 & 15 & 17 & 54 & 10 & 37.51 & -118.84 & 8.0 & 4.89 & 4.08 & 0.33 & 7 \\
\hline 1999 & 05 & 17 & 06 & 37 & 20 & 37.54 & -118.80 & 3.6 & 3.86 & 3.16 & 0.18 & 8 \\
\hline 1999 & 08 & 01 & 16 & 27 & 20 & 37.35 & -117.05 & 26.4 & 4.70 & 4.06 & 0.17 & 8 \\
\hline 1999 & 08 & 02 & 05 & 40 & 27 & 37.39 & -117.06 & 1.8 & 3.60 & 3.25 & 0.14 & 6 \\
\hline 1999 & 08 & 02 & 06 & 5 & 14 & 37.30 & -117.06 & 14.8 & 5.10 & 4.36 & 0.27 & 10 \\
\hline 1999 & 11 & 08 & 01 & 53 & 13 & 37.40 & -118.60 & 5.0 & 3.60 & 3.15 & 0.16 & 7 \\
\hline 2001 & 05 & 17 & 21 & 53 & 45 & 35.73 & -118.02 & 4.2 & 4.05 & 2.98 & 0.08 & 8 \\
\hline 2001 & 07 & 17 & 12 & 59 & 59 & 35.95 & -117.90 & 0.4 & 4.60 & 4.42 & 0.17 & 9 \\
\hline 2001 & 08 & 02 & 16 & 21 & 19 & 37.22 & -117.79 & 9.0 & 3.95 & 3.22 & 0.12 & 4 \\
\hline 2002 & 06 & 14 & 12 & 40 & 44 & 36.72 & -116.30 & 11.9 & 4.31 & 3.92 & 0.17 & 5 \\
\hline 2002 & 09 & 28 & 10 & 34 & 47 & 35.95 & -117.30 & 3.7 & 4.10 & 3.25 & 0.21 & 7 \\
\hline 2003 & 01 & 25 & 09 & 16 & 10 & 35.32 & -118.65 & 5.6 & 4.39 & 3.95 & 0.30 & 6 \\
\hline 2003 & 03 & 08 & 15 & 35 & 02 & 37.57 & -118.89 & 5.5 & 3.71 & 3.19 & 0.18 & 5 \\
\hline
\end{tabular}

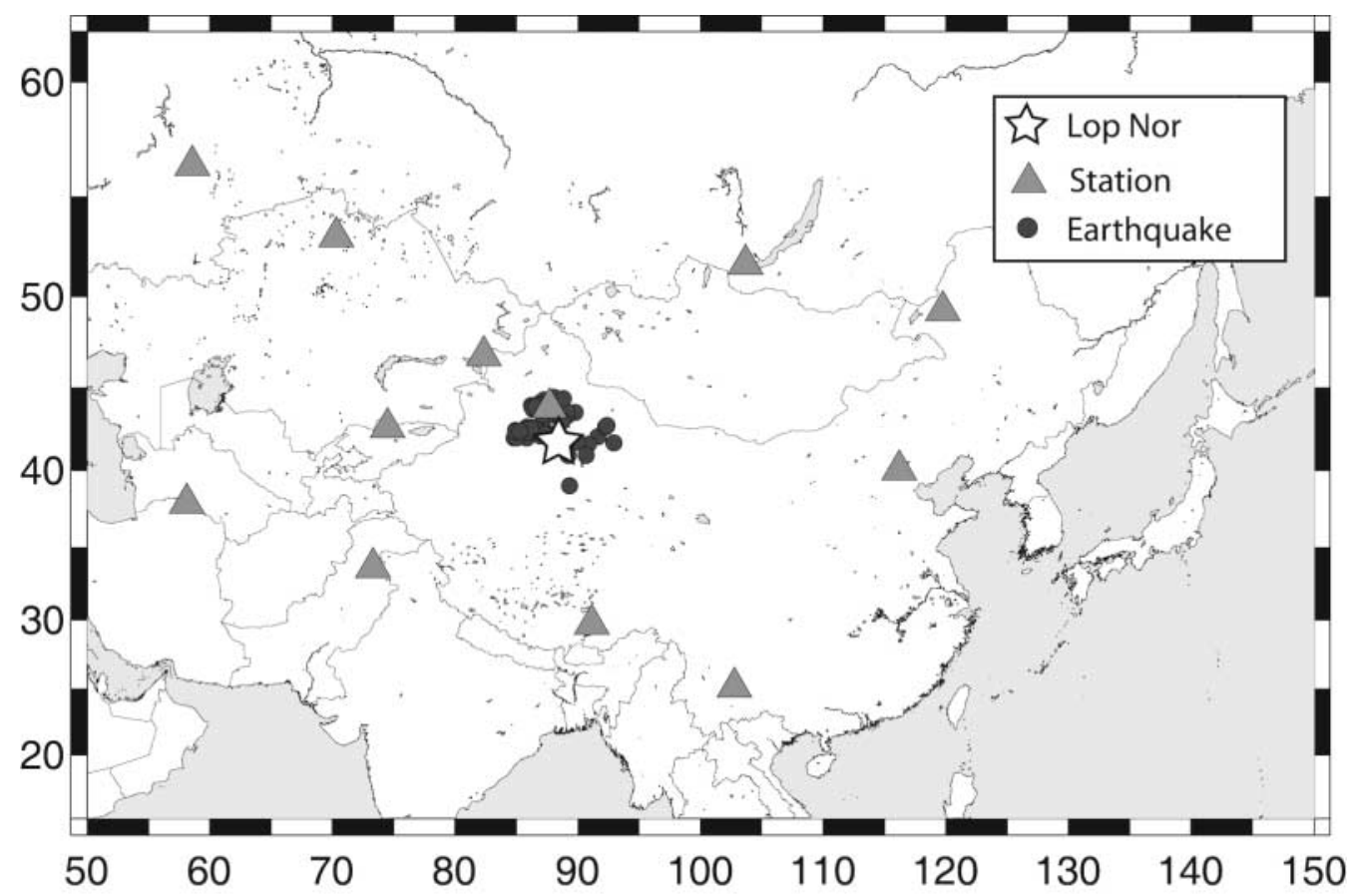

Figure 12. Test dataset consisting of Lop Nor explosions recorded on regional and near-teleseismic stations (filled triangles) together with western Chinese earthquakes (filled circles).

Table 4

Origin Information and $M_{\mathrm{s}}(\mathrm{VMAX})$ Test Results for Explosions at Lop Nor

\begin{tabular}{|c|c|c|c|c|c|c|c|c|c|c|c|c|}
\hline Year & Month & Day & Hour & Minute & Second & Latitude & Longitude & Depth & $m_{\mathrm{b}}$ & $\begin{array}{c}M_{\mathrm{s}} \\
(\mathrm{VMAX})\end{array}$ & STD & No. \\
\hline 1992 & 05 & 21 & 04 & 59 & 47 & 41.51 & 88.77 & 0 & 6.5 & 5.06 & 0 & 1 \\
\hline 1992 & 09 & 25 & 07 & 59 & 58 & 41.72 & 88.34 & 0 & 5 & 2.98 & 0 & 1 \\
\hline 1993 & 10 & 05 & 01 & 59 & 56 & 41.67 & 88.70 & 0 & 5.9 & 4.09 & 0.24 & 3 \\
\hline 1994 & 06 & 10 & 06 & 25 & 57 & 41.53 & 88.71 & 0 & 5.8 & 3.51 & 0 & 1 \\
\hline 1994 & 10 & 07 & 03 & 25 & 58 & 41.66 & 88.75 & 0 & 6 & 4.02 & 0.08 & 6 \\
\hline 1995 & 05 & 15 & 04 & 05 & 57 & 41.60 & 88.82 & 0 & 6.1 & 4.13 & 0.19 & 6 \\
\hline 1995 & 08 & 17 & 00 & 59 & 57 & 41.56 & 88.80 & 0 & 6 & 4.15 & 0.13 & 6 \\
\hline 1996 & 06 & 08 & 02 & 55 & 58 & 41.66 & 88.69 & 0 & 5.9 & 4.07 & 0.1 & 7 \\
\hline 1996 & 07 & 29 & 1 & 48 & 57 & 41.82 & 88.42 & 0 & 4.9 & 3.01 & 0.18 & 5 \\
\hline
\end{tabular}


Table 5

Origin Information and $M_{\mathrm{s}}(\mathrm{VMAX})$ Test Results for Earthquakes Near Lop Nor

\begin{tabular}{|c|c|c|c|c|c|c|c|c|c|c|c|c|}
\hline Year & Month & Day & Hour & Minute & Second & Latitude & Longitude & Depth & $m_{\mathrm{b}}$ & $\begin{array}{c}M_{\mathrm{s}} \\
(\mathrm{VMAX})\end{array}$ & STD & Stations \\
\hline 1995 & 08 & 02 & 11 & 59 & 43 & 41.63 & 88.45 & 10 & 4.1 & 3.32 & 0 & 1 \\
\hline 1995 & 09 & 04 & 18 & 43 & 45 & 43.90 & 87.44 & 33 & 4.1 & 2.91 & 0.13 & 5 \\
\hline 1995 & 12 & 12 & 17 & 31 & 16 & 42.12 & 86.91 & 33 & 4.3 & 3.32 & 0.2 & 6 \\
\hline 1996 & 03 & 04 & 14 & 02 & 22 & 44.12 & 87.20 & 33 & 3.9 & 3.22 & 0.07 & 4 \\
\hline 1996 & 03 & 20 & 02 & 11 & 21 & 42.18 & 87.63 & 24 & 4.8 & 3.76 & 0.2 & 9 \\
\hline 1996 & 03 & 31 & 03 & 07 & 14 & 43.02 & 88.68 & 33 & 4.2 & 3.24 & 0.21 & 6 \\
\hline 1996 & 05 & 12 & 01 & 00 & 38 & 43.67 & 86.96 & 33 & 3.7 & 2.95 & 0.22 & 2 \\
\hline 1997 & 02 & 08 & 17 & 12 & 09 & 42.34 & 86.99 & 9 & 4.6 & 3.54 & 0.35 & 2 \\
\hline 1997 & 05 & 27 & 01 & 56 & 24 & 42.62 & 86.16 & 21 & 4.9 & 3.64 & 0.14 & 7 \\
\hline 1997 & 06 & 08 & 20 & 25 & 53 & 39.06 & 89.28 & 33 & 4.7 & 3.2 & 0.17 & 7 \\
\hline 1998 & 01 & 20 & 19 & 35 & 04 & 42.01 & 84.75 & 33 & 3.5 & 2.75 & 0 & 1 \\
\hline 1998 & 02 & 07 & 22 & 42 & 44 & 42.55 & 86.01 & 33 & 4.1 & 3.1 & 0.11 & 3 \\
\hline 1998 & 04 & 13 & 23 & 14 & 32 & 41.99 & 85.80 & 33 & 4 & 2.92 & 0.28 & 2 \\
\hline 1998 & 08 & 19 & 12 & 26 & 19 & 43.81 & 86.33 & 19 & 4.6 & 3.71 & 0.2 & 9 \\
\hline 1998 & 10 & 20 & 18 & 39 & 23 & 42.56 & 87.15 & 33 & 4.7 & 3.2 & 0.12 & 7 \\
\hline 1999 & 01 & 27 & 06 & 25 & 01 & 41.62 & 88.36 & 33 & 4.5 & 3.36 & 0.16 & 8 \\
\hline 1999 & 01 & 30 & 03 & 51 & 05 & 41.67 & 88.46 & 23 & 5.9 & 5.25 & 0.14 & 6 \\
\hline 1999 & 04 & 29 & 05 & 27 & 55 & 41.62 & 90.82 & 33 & 4.3 & 3.26 & 0.21 & 8 \\
\hline 1999 & 05 & 01 & 13 & 48 & 52 & 42.04 & 87.96 & 21 & 4.2 & 2.96 & 0.21 & 5 \\
\hline 1999 & 05 & 17 & 04 & 52 & 34 & 42.28 & 87.92 & 33 & 4.2 & 2.92 & 0.35 & 3 \\
\hline 1999 & 10 & 18 & 02 & 42 & 20 & 41.77 & 89.25 & 33 & 5 & 4.25 & 0.15 & 8 \\
\hline 2000 & 10 & 03 & 03 & 07 & 28 & 41.99 & 84.92 & 33 & 5.2 & 4.37 & 0.28 & 7 \\
\hline 2001 & 03 & 13 & 03 & 18 & 38 & 42.39 & 86.12 & 24 & 4.7 & 3.67 & 0.11 & 9 \\
\hline 2001 & 12 & 21 & 23 & 05 & 50 & 43.74 & 86.53 & 10 & 4.5 & 3.68 & 0.2 & 9 \\
\hline 2002 & 01 & 13 & 05 & 27 & 16 & 43.36 & 89.04 & 33 & 4.3 & 3.22 & 0.18 & 9 \\
\hline 2002 & 03 & 11 & 23 & 26 & 49 & 42.39 & 85.90 & 33 & 4.6 & 3.52 & 0.14 & 9 \\
\hline 2002 & 10 & 02 & 09 & 50 & 52 & 43.57 & 89.08 & 29 & 4.6 & 3.32 & 0.06 & 3 \\
\hline 2002 & 10 & 07 & 03 & 01 & 47 & 43.42 & 87.09 & 29 & 4.8 & 3.98 & 0.11 & 8 \\
\hline 2003 & 01 & 22 & 13 & 33 & 02 & 42.21 & 87.33 & 24 & 4.7 & 3.33 & 0.23 & 9 \\
\hline 2003 & 02 & 13 & 18 & 32 & 47 & 41.91 & 88.24 & 51 & 4.3 & 3.5 & 0.22 & 9 \\
\hline 2003 & 02 & 23 & 22 & 34 & 20 & 43.75 & 87.71 & 33 & 4.2 & 3.13 & 0.22 & 9 \\
\hline 2003 & 03 & 13 & 15 & 07 & 07 & 41.80 & 89.08 & 33 & 4.8 & 3.64 & 0.19 & 9 \\
\hline 2003 & 07 & 03 & 05 & 53 & 52 & 43.85 & 86.26 & 37 & 4.8 & 4.09 & 0.21 & 7 \\
\hline 2003 & 08 & 24 & 21 & 54 & 36 & 44.30 & 87.20 & 33 & 4.1 & 3.11 & 0.21 & 8 \\
\hline 2003 & 12 & 19 & 15 & 01 & 22 & 41.95 & 88.85 & 33 & 4.7 & 3.82 & 0.18 & 3 \\
\hline 2004 & 01 & 29 & 15 & 29 & 08 & 42.54 & 86.13 & 15 & 4.3 & 3.14 & 0.09 & 6 \\
\hline 2004 & 03 & 20 & 22 & 55 & 03 & 43.87 & 86.50 & 10 & 4.1 & 3.25 & 0.14 & 3 \\
\hline 2004 & 03 & 29 & 20 & 30 & 32 & 43.04 & 88.65 & 21 & 4.2 & 2.9 & 0.33 & 4 \\
\hline
\end{tabular}

Table 6

Origin Information and $M_{\mathrm{s}}(\mathrm{VMAX})$ Test Results for Additional Eurasian Explosions

\begin{tabular}{|c|c|c|c|c|c|c|c|c|c|c|c|c|}
\hline Year & Month & Day & Hour & Minute & Second & Latitude & Longitude & $m_{\mathrm{b}}$ & $\begin{array}{c}M_{\mathrm{s}} \\
(\mathrm{VMAX})\end{array}$ & STD & No. & Test Site \\
\hline 1989 & 10 & 19 & 9 & 49 & 59 & 49.927 & 78.972 & 6 & 4.38 & 0.07 & 3 & Shagan \\
\hline 1989 & 10 & 04 & 11 & 30 & 0 & 49.751 & 78.005 & 4.7 & 3.23 & 0 & 1 & Shagan \\
\hline 1989 & 09 & 02 & 4 & 16 & 59 & 50.019 & 78.998 & 5.1 & 3.29 & 0.24 & 2 & Shagan \\
\hline 1989 & 07 & 08 & 3 & 47 & 0 & 49.869 & 78.775 & 5.6 & 3.78 & 0.15 & 3 & Shagan \\
\hline 1989 & 02 & 12 & 4 & 15 & 9 & 49.911 & 78.704 & 5.9 & 4.24 & 0 & 1 & Shagan \\
\hline 1989 & 01 & 22 & 3 & 57 & 9 & 49.934 & 78.815 & 6.1 & 4.28 & 0 & 1 & Shagan \\
\hline 1988 & 12 & 17 & 4 & 18 & 9 & 49.879 & 78.924 & 5.9 & 4.15 & 0 & 1 & Shagan \\
\hline 1988 & 11 & 23 & 3 & 57 & 9 & 49.767 & 78.029 & 5.4 & 3.56 & 0 & 1 & Shagan \\
\hline 1990 & 10 & 24 & 14 & 57 & 58 & 73.331 & 54.757 & 5.7 & 4.08 & 0.17 & 7 & Novaya Zemlya \\
\hline 1998 & 05 & 11 & 10 & 13 & 44 & 27.078 & 71.719 & 5.2 & 3.17 & 0.11 & 8 & India \\
\hline 1998 & 05 & 28 & 10 & 16 & 17 & 28.83 & 64.95 & 4.9 & 3.27 & 0.18 & 8 & Pakistan \\
\hline
\end{tabular}



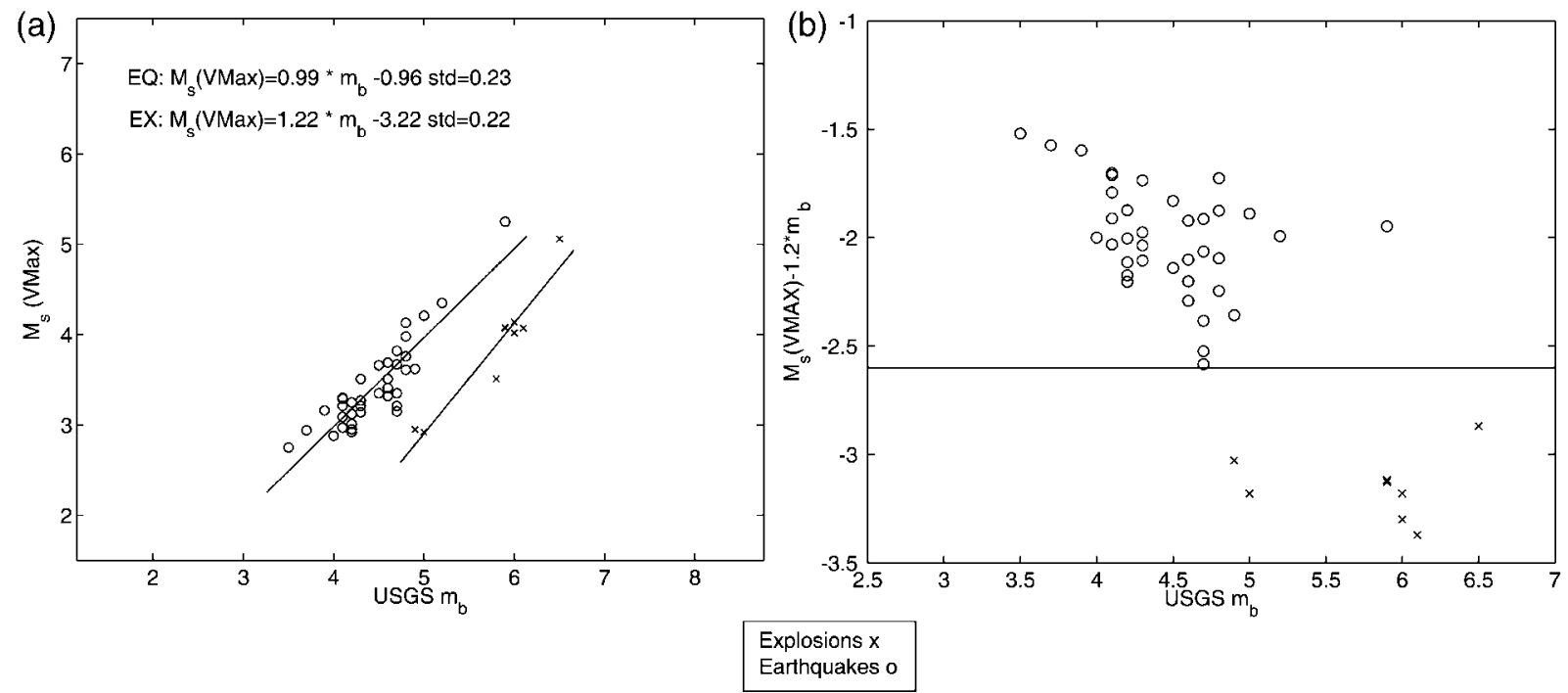

Figure 13. Discrimination results for $M_{\mathrm{s}}(\mathrm{VMAX})$ at the Lop Nor Test Site. (a) $M_{\mathrm{s}}$ (VMAX) versus $m_{\mathrm{b}}$ for earthquakes in northwestern China and nuclear explosions at Lop Nor. (b) Linear discrimination of the two datasets showing the decision line $(-2.6)$ for classifying an event as a possible nuclear explosion.

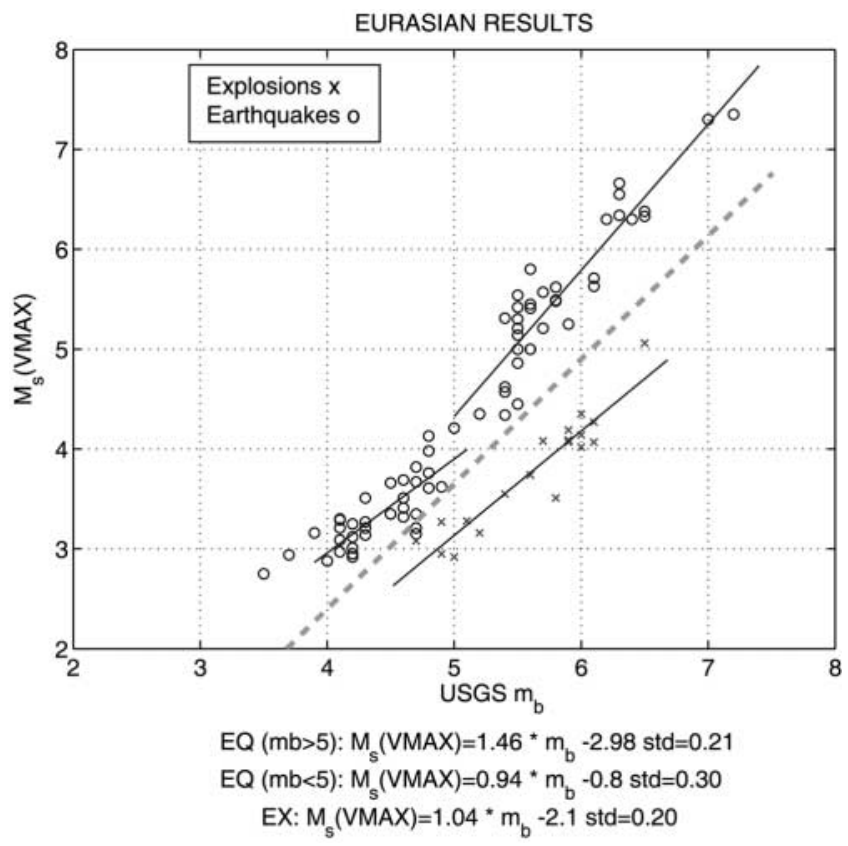

Figure 14. $M_{\mathrm{s}}-m_{\mathrm{b}}$ relationships for all Eurasian earthquake and explosion data for which an $M_{\mathrm{s}}$ (VMAX) was estimated during this study. The bodywave magnitudes are all from the United States Geological Survey. We split the earthquake data at $m_{\mathrm{b}}=$ 5 based on corner frequency effects for earthquakes and $m_{\mathrm{b}}$. The earthquake and explosion populations both have slopes that are approximately 1 for $m_{\mathrm{b}}<5$ and are separated by an average of 0.90 m.u. The dashed line is the Murphy et al. (1997) criterion for event screening. for our earthquake and explosion populations at $m_{\mathrm{b}}$ values $<5$ are similar to the Lambert and Alexander (1971) results. Additionally, we observed 0.90 m.u. separation between the two populations at $m_{\mathrm{b}}$ values below 5 , whereas Lambert and Alexander (1971) noted a difference of 0.82 m.u., based on the fitted regression lines for their NTS earthquakes and explosions. Although more data will be required to finalize the two-slope hypothesis, these preliminary results suggest that the discrimination of explosions from earthquakes can be achieved at lower magnitudes using the Russell (2006) formula and the $M_{\mathrm{s}}(\mathrm{VMAX})$ measurement technique.

Murphy et al. (1997) determined an event-screening relationship based on $M_{\mathrm{s}}-m_{\mathrm{b}}$ estimates. For USGS-estimated $m_{\mathrm{b}}$, the screening criterion is:

$$
M_{\mathrm{s}}=1.25 m_{\mathrm{b}}-2.60 \text {. }
$$

We plotted the Murphy et al. (1997) criterion in Figure 14 as the dashed line and note that two of the earthquakes fall below this line. More importantly, none of our explosions plotted above this line.

\section{Conclusions}

The Russell surface-wave magnitude formula and the $M_{\mathrm{s}}(\mathrm{VMAX})$ measurement technique provide a new method for estimating surface-wave magnitudes. The new method has several benefits. First, the technique allows for timedomain measurements of surface-wave amplitudes, giving an analyst the ability to visually confirm that the pick is 
correct and is an actual surface wave. Also, it allows for surface-wave magnitudes to be measured at local and regional distances where traditional 20-sec magnitudes cannot be used. And these magnitudes are not biased with respect to teleseismic estimates using the same $M_{\mathrm{s}}(\mathrm{VMAX})$ measurement technique. Additionally, the application of narrowband Butterworth-filtering techniques appropriately handles Airy phase phenomena that, before this study, had to be accounted for by using Marshall and Basham's (1972) empirical corrections. Finally, because the method is variable period and not restricted to near 20 -sec period, the analyst is allowed to measure $M_{\mathrm{s}}$ where the signal is largest. The new method has been successfully tested on three research datasets, and the results suggest that the method can be used to screen out a large percentage of small earthquakes at $m_{\mathrm{b}}$ $<5$. Thus, we are currently implementing the technique for operational testing.

\section{Acknowledgments}

The data used in this study come from a variety of sources. We thank the following organizations for providing access to their data: the Geological Survey of Canada; Institut de Physique du Globe de Paris; GFZ Potsdam, Germany; U.S. Geological Survey, National Science Foundation, University of California, San Francisco; California Institute of Technology; Lamont Doherty Earth Observatory; and Istituto Nazionale di Geofisica e Vulcanologia, Rome, Italy. We are also indebted to Howard Patton for his assistance in the LNN database acquisition and his comments concerning various aspects of the research. We also thank Bill Walter and Marv Denny for help in acquiring the MNV dataset (Denny, 1998). We are grateful to Mark Leidig and Ileana Tibuleac, who helped with database preparation, and to Jack Murphy, Heather Hooper, and James Lewkowicz for insightful discussions about the article and research. Karl Veith and an anonymous reviewer helped improve the article during the review process. We thank the developers of the Generic Mapping Tools software (Wessel and Smith, 1998), Computer Programs in Seismology (Herrmann, 2004), and Matlab, all of which were used to generate and present the results of our research. We are also grateful to Harvard University for making their CMT estimates readily available. This research was sponsored by the U.S. Air Force Research Laboratory and the Defense Threat Reduction Agency under Contract DTRA01-01-C-0080

\section{References}

Alexander, S. S. (2002). Seismic monitoring for underground nuclear explosions, in Science, Technology and National Security, S. K. Majumbar, S. S. Alexander, L. M. Rosenfeld, M. F. Rieders, E. W. Miller, and A. I. Panah (Editors), The Pennsylvania Academy of Sciences, Easton, Pennsylvania, 267 pp.

Bonner, J., and R. B. Herrmann (2004). A Synthetic $M_{\mathrm{s}}-m_{\mathrm{b}}$ study, Weston Geophysical Scientific Report, 20 pp.

Bonner, J., D. Harkrider, E. T. Herrin, R. H. Shumway, S. A. Russell, and I. M. Tibuleac (2003). Evaluation of short-period, near-regional $M_{\mathrm{s}}$ scales for the Nevada Test Site. Bull. Seism. Soc. Am. 93, 1773-1791.

Bonner, J. L., D. T. Reiter, and D. Harkrider (2004). Development of a time-domain, variable-period surface wave magnitude measurement procedure for application at regional distances, in Proc. of the 26th Annual Seismic Research Review Meeting, Orlando, Florida.

Chael, E. P. (1997). An automated Rayleigh-wave detection algorithm, Bull. Seism. Soc. Am. 87, 157-163.
Denny, M. D. (1998). Mina seismic data: historic background for CTBT monitoring, Lawrence Livermore Report UCRL-MI-130657.

Denny, M. D., S. R. Taylor, and E. S. Vergino (1987). Investigation of $m_{\mathrm{b}}$ and $M_{\mathrm{s}}$ formulas for the western United States and their impact on the $M_{\mathrm{s}} / m_{\mathrm{b}}$ discriminant, Bull. Seism. Soc. Am. 77, 987-995.

Denny, M. D., S. R. Taylor, and E. S. Vergino (1989). Erratum: investigation of $m_{\mathrm{b}}$ and $M_{\mathrm{s}}$ formulas for the western United States and their impact on the $M_{\mathrm{s}} / m_{\mathrm{b}}$ discriminant, Bull. Seism. Soc. Am. 79, 230.

Dziewonski, A. M., J. Bloch, and M. Landisman (1969). A new technique for the analysis of transient seismic signals, Bull. Seism. Soc. Am. 59, 427-444.

Gutenberg, B. (1945). Amplitudes of surface waves and the magnitudes of shallow earthquakes, Bull. Seism. Soc. Am. 35, 3.

Herak, M., and D. Herak (1993). Distance dependence of $M_{s}$ and calibrating function for 20 second Rayleigh waves, Bull. Seism. Soc. Am. 83, 1681.

Herrmann, R. B. (2004). Computer Programs in Seismology Version 3.30, St. Louis University, St. Louis, Missouri.

Kanamori, H., and G. S. Stewart (1976). Mode of strain release along the Gibbs Fracture Zone, Mid-Atlantic Ridge, Phys. Earth Planet. Interiors 11, 312-332.

Lambert, D. G., and S. S. Alexander (1971). Relationship of body and surface wave magnitudes for small earthquakes and explosions, SDL Report 245, Teledyne Geotech, Alexandria, Virginia.

Marshall, P. D., and P. W. Basham (1972). Discrimination between earthquakes and underground explosions employing an improved $M_{\mathrm{s}}$ scale, Geophys. J. R. Astr. Soc. 29, 431-458.

Murphy, J. R., B. W. Barker, and M. E. Marshall (1997). Event screening at the IDC using the Ms/mb discriminant, Maxwell Technologies Final Report, 23 pp.

Nuttli, O. W. (1983). Average seismic source-parameter relations for midplate earthquakes, Bull. Seism. Soc. Am. 73, 519-535.

Okal, E. A. (1989). A theoretical discussion of time domain magnitudes: the Prague formula for $M_{\mathrm{s}}$ and the mantle magnitude $M_{\mathrm{m}}, J$. Geophys. Res. 94, 4194-4204.

Patton, H. (2001). Regional magnitude scaling, transportability, and $M_{\mathrm{s}}-m_{\mathrm{b}}$ discrimination at small magnitudes, in Monitoring the Comprehensive Nuclear Test Ban Treaty: Source Processes and Explosion Yield Determination, G. Ekstrom, M. Denny, and J. R. Murphy (Editors), Pure Appl. Geophys. 158, 1951-2015.

Rezapour, M., and R. G. Pearce (1998). Bias in surface-wave magnitude $M_{\mathrm{s}}$ due to inadequate distance correction, Bull. Seism. Soc. Am. 88, 43-61.

Russell, D. R. (2006). Development of a time-domain, variable-period surface wave magnitude measurement procedure for application at regional and teleseismic distances, part I: theory, Bull. Seism. Soc. Am. 96, no. 2, 665-677.

Selby, N. (2001). Association of Rayleigh waves using back azimuth measurements: application to test ban verification, Bull. Seism. Soc. Am. 91, 580-593.

Stevens, J. L., and S. M. Day (1985). The physical basis of the mb:Ms and variable frequency magnitude methods for earthquake/explosion discrimination, J. Geophys. Res. 90, 3009-3020.

Stevens, J. L., and K. L. McLaughlin (2001). Optimization of surface wave identification and measurement, in Monitoring the Comprehensive Nuclear Test Ban Treaty: Surface Waves, A. Levshin and M. H. Ritzwoller (Editors), Pure Appl. Geophys. 158, 1547-1582.

Stevens, J. L., D. A. Adams, and E. Baker (2001). Surface wave detection and measurement using a one-degree global dispersion grid, SAIC Final Report SAIC-01/1085.

Vanĕk, J., A. Zatopek, V. Karnik, Y. V. Riznichenko, E. F. Saverensky, S. L. Solov'ev, and N. V. Shebalin (1962). Standardization of magnitude scales, Bull. Acad. Sci. U.S.S.R., Geophys. Ser. 2, 108 (in English). 
Vergino, E. S., and R. W. Mensing (1989). Yield estimation using regional $m_{\mathrm{b}}(P n)$, Lawrence Livermore National Laboratory Report UCID101600.

von Seggern, D. (1977). Amplitude distance relation for 20-second Rayleigh waves, Bull. Seism. Soc. Am. 67, 405-411.

Wessel, P., and W. H. F. Smith (1998). New, improved version of the Generic Mapping Tools Released, EOS, Trans. AGU 79, 579.

Woods, B., and D. G. Harkrider (1995). Determining surface-wave magnitudes from regional Nevada Test Site data, Geophys. J. Int. 120, 474-498.

Yacoub, N. K. (1983). Instantaneous amplitudes: a new method to measure seismic magnitude, Bull. Seism. Soc. Am. 73, 1345-1355.

Weston Geophysical Corporation

4000 S. Medford Suite $10 \mathrm{~W}$

Lufkin, Texas 75904

bonner@westongeophysical.com (J.L.B.)
Air Force Technical Applications Center

Patrick Air Force Base, Florida (D.R.R.)

Weston Geophysical Corporation

57 Bedford Street, Suite 102

Lexington, Massachusetts 02420

hark@ourconcord.net

delaine@westongeophysical.com

(D.G.H., D.R.)

Department of Earth \& Atmospheric Sciences

Saint Louis University

3507 Laclede Avenue

St. Louis, Missouri 63103

rbh@eas.slu.edu

(R.B.H.)

Manuscript received 21 March 2005. 